\title{
Performance assessment of existing models to predict brittle failure modes of steel-to-timber connections loaded parallel-to-grain with dowel-type fasteners
}

\author{
J. M. Cabrero ${ }^{\mathrm{a}, *}$, M. Yurrita \\ ${ }^{a}$ Wood Chair. Department of Building Construction, Services and Structures. University of Navarra. 31009
}

Pamplona (Spain)

\begin{abstract}
For safety reasons, ductile failure in timber connections with dowel-type fasteners is always recommended. It has usually been assumed that it can be achieved by fulfilling minimum spacing requirements between fasteners. However, recent works address the need to account for brittle failure modes (namely splitting, row-shear, and block and plug-shear) in connections loaded parallel-to-the-grain in an explicit manner, in order to evaluate them and achieve the desired ductility. This article describes the brittle failure modes and reviews the existing calculation models proposed by several authors -some of them included in standards-. Finally, the performance of these models is assessed against an extensive database of tests gathered from the literature following a comprehensive methodology.
\end{abstract}

Keywords:

Brittle failure parallel-to-grain, Splitting, Row-shear failure, Block-shear failure, Plug-shear failure, Timber connections

\section{Introduction}

It is well known that connections are of crucial importance in the behaviour of a structure, not only in terms of cost or influence on the global structural behaviour, but also in terms of safety. They have been reported to be involved in almost one quarter of recent collapses of timber structures, where more than half of the involved connections were with dowel-type fasteners [1, 2].

\footnotetext{
This article has been published in Engineering Structures.

Please refer it as: J.M. Cabrero, M. Yurrita, Performance assessment of existing models to predict brittle failure modes of steel-to-timber connections loaded parallel-to-grain with dowel-type fasteners, Engineering Structures, Volume 171, 2018, Pages 895-910, ISSN 0141-0296, https://doi.org/10.1016/j. engstruct.2018.03.037

${ }^{*}$ Corresponding author

Email addresses: jcabrero@unav.es (J. M. Cabrero), myurrital@alumni.unav.es ( M. Yurrita)
}

Postprint. Article published in Engineering Structures. doi: 10.1016/j.engstruct.2018.03.037 
The European Yield Model, included in the Eurocode 5 [3] dates back to early works by Johansen [4] and only provides the capacity for the ductile failure mode of joints, which is governed by the embedment of the timber or the bending of the doweltype fasteners. It is assumed that no brittle failure occurs if the given minimum spacing requirements are met.

However, connections in construction practice include a number of fasteners larger than those currently investigated in the laboratories. As a consequence, the joint capacity could be governed by a brittle failure mode [5]. Nevertheless, designers are not aware of this fact, as shown by a survey conducted in the European area by the Working Group 3 of the COST Action FP1402 [6, 7]: more than 30\% of the participants (designers, engineers, constructors. . .) did not know about their existence (even up to $24 \%$ among those with more than 10 years of experience in the field of timber structures).

Some well-known building collapses were originated by a brittle failure of the connections, as the Siemens Arena and the Jyväskilä Fair roof [1, 8]. In the case of the Utopia pavilion [5], a previous experimental campaign pointed out the resulting brittle failure, and collapse was prevented at the cost of reinforcing the connections on-site with glued-in-rods.

The prenormative version of the Eurocode [9] had been used in both the Jyväskilä Fair roof [8] and the Utopia pavilion [5]. It was demonstrated that it did not cover brittle failure in an adequate way [10, 5]. Those experiences gave rise to a brief description in Racher [11], and a proposal from Ranta-Maunus and Kevarinmäki [10] of a supplement to the Eurocode 5 concerning the calculation of block shear failure. Both stand as the origin of the current Annex A of the Eurocode 5 [3].

Brittle failure modes had until then been grouped under the so-called group effect concept [12], which assumed that an interaction effect among the fasteners exists, and as a result the total capacity of the connection is reduced [13]. Nozynski [14], in 1980, was one of the first authors to notice fracture of wood along the row of nails, and proposed the introduction of an effective number of fasteners. Several similar design equations were suggested during the development of the Eurocode 5 [15- 17], and were soon adopted by different countries in their design standards [18].

However, Smith and Steck [19] noticed already in 1985 the need for new theories to obtain the "ultimate capacities of joints with brittle failures". Since then, several references introduced the concept of brittle failure. Among them, the STEP books, where Racher [11] provides a brief explanation of this concept for dowelled connections, and Kevarinmäki [20] describes it for nailed connections in trusses.

Several model proposals for the different types of brittle failure have been made: for splitting [3, 21, 22], row-shear [23, 22] block-shear models for dowelled [23, 24], nailed [25, 26] and riveted connections [27,-33]; some of them are fracture-mechanics based models, mainly for splitting and row-shear [34, 16, 35-37]. Most of them will be reviewed in this paper.

Brittle failures, such as block and row-shear models were introduced in the early 2000s in the Canadian Code O86 [38, 24, 39-42]. In the case of the Eurocode 5 [3], splitting and row-shear failures are implicitly taken into account by means of the effective number of fasteners based on the work by Jorissen [16]. A model for block and plug-shear is included as Annex A [3], dating back to the previously referred proposals 52 [11, 10]. Currently, the subject is under consideration in the New Zealand Standard 
draft [43] and in the future Eurocode 5. Within the COST Action FP 1402 [7], which aims to prepare background documents for the future Eurocode 5, Working Group 3 has been in charge of the review of the different proposals for this type of failure, which this article summarizes.

This work provides insight into the different brittle failure modes of steel-to-timber connections with dowel-type fasteners loaded parallel-to-grain. It compiles the different available models in an ordered and coherent way, and benchmarks them against experimental tests compiled from the literature.

Special attention is given to those models which aim at providing a complete and consistent set of equations to discriminate among ductile and brittle failures. Such a complete method is nowadays provided in the New Zealand Standard draft [43], and the method for dowelled connections by Hanhijärvi and Kevarinmäki [44, 22]. It may be argued that also a complete model is given in the Eurocode 5 [3], although some failure modes are implicitly taken into account.

The paper is organised as follows: first, the different failure modes and parameters of connections loaded parallel-to-grain are described in Section 2. Section 3 reviews the different existing models for each failure mode. Section 4 provides information about the experimental data set, and the methodology used to compare and benchmark the different models. Special attention is given to the different possible metrics to assess the performance of the models. The results concerning the prediction ability and reliability will be discussed in Section 5 .

\section{Brittle failure modes in connections loaded parallel-to-the-grain}

\subsection{Geometry and types of connections loaded parallel-to-the-grain}

Connections with dowel-type fasteners loaded parallel-to-grain (as shown in Figure 1) are often made by means of different types of fasteners e.g. nails, dowels, bolts, (self-tapping) screws. Their number in a connection greatly depends on the type of fastener used, i.e. small diameter fasteners like nails or rivets are often used with a larger quantity within one connection. Only connections made in combination with steel plates are dealt with in this paper. All the different connection configurations considered here are shown in Figure 2. Since the different models give the capacity per shear plane or wood member, the number of shear planes $n_{s}$ and wood members $n_{w}$ for each configuration are given in Figure 2 as well.

The geometrical parameters and denotations of a typical steel-timber connection with dowel-type fasteners loaded parallel-to-grain are given in Figure 1. This nomenclature will be used in this paper, and all the model equations will be rewritten accordingly.

The dimension of the timber member is defined by its width $b$ and thickness $t$. The relevant connection parameters are mainly related to the spacing of the fasteners in the parallel $a_{1}$ and perpendicular $a_{2}$ to-the-grain directions, which are usually defined in relation to the fastener diameter $d$. The edge distances are named $a_{3}$ for the enddistance in the parallel direction, and $a_{4}$ in the perpendicular direction. These distances have been usually considered a requirement to achieve the desired ductile failure mode [3]. 

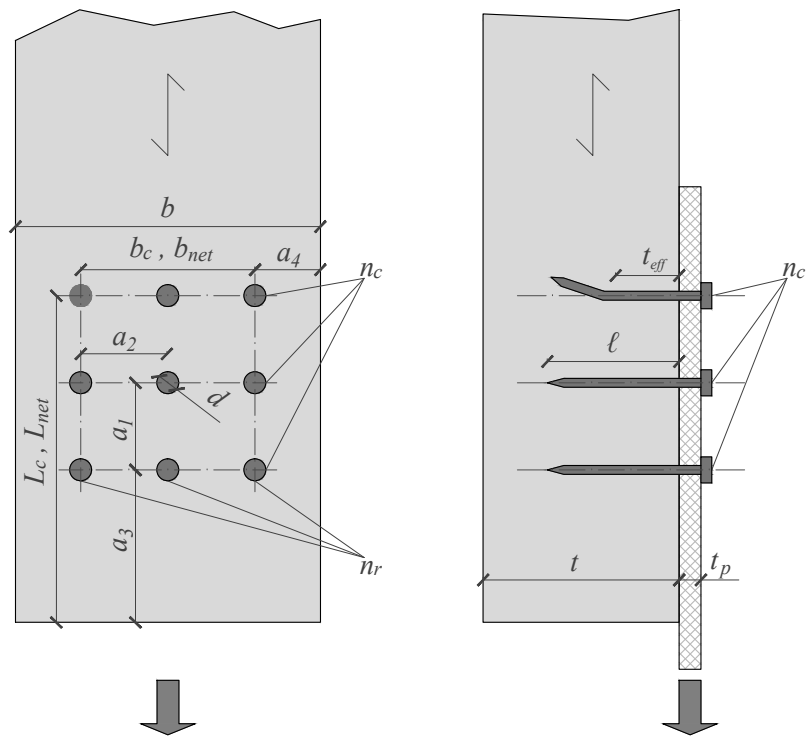

Figure 1: Denotation of connection geometrical parameters used in this paper, depicted for the case of a wood-steel WS connection with small diameter fasteners, as shown in Figure 2a

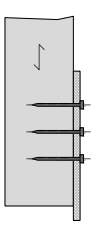

(a) $W S$

$\left(n_{s}=1\right.$,

$\left.n_{w}=1\right)$

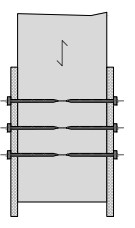

(b) $S W S$

$\left(n_{s}=2\right.$,

$\left.n_{w}=1\right)$

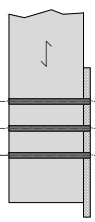

(c) WS

( $n_{s}=1$,

$\left.n_{w}=1\right)$

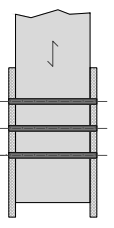

(d) $S W S$

( $n_{s}=2$,

$n_{w}=1$ )

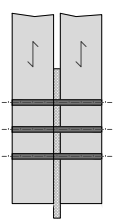

(e) WSW

$\left(n_{s}=2\right.$,

$n_{w}=2$ )

Figure 2: Joint configurations of steel-timber connections: small fasteners (a) and (b), and large fasteners (c)-(e). $S=$ steel, $W=$ wood; $n_{s}=$ number of shear planes, $n_{w}=$ number of wood members. 


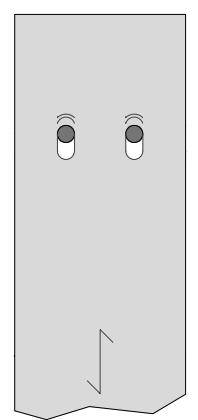

(a) Embedment

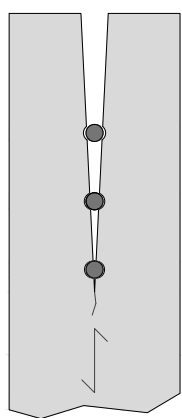

(b) Splitting

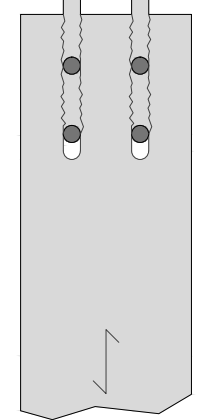

(c) Row shear

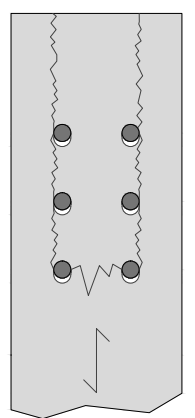

(d) Block and plug shear

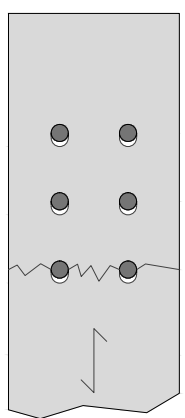

(e) Net tension

Figure 3: Different possible failure modes of connections loaded parallel-to-grain. Embedment (a) is the only ductile failure mode, the rest are brittle.

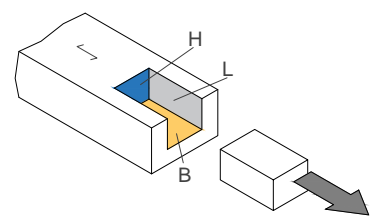

(a) Mode a $(\mathbf{L}+\mathbf{H}+\mathbf{B})$

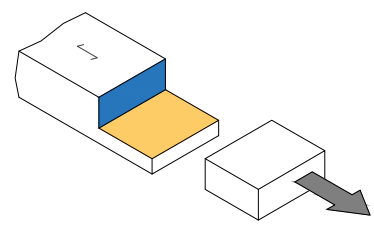

(b) Mode b $(\mathbf{B}+\mathbf{H})$

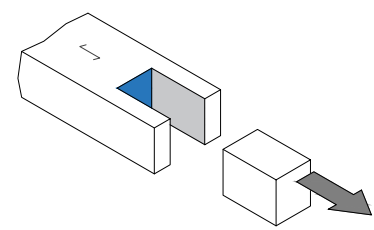

(c) Mode c $(\mathbf{L}+\mathbf{H})$

Figure 4: Different possible failure modes of group tear-out.

The connection area can be defined by its length $L_{c}$ and width $b_{c}$, where $L_{c}=$ $a_{1}\left(n_{c}-1\right)+a_{3}$ and $b_{c}=b-2 a_{4}=\left(n_{r}-1\right) a_{2}$. Additionally, the net length, $L_{n e t}=$ $L_{c}-\left(n_{c}-\frac{1}{2}\right) d$, and width, $b_{n e t}=b_{c}-\left(n_{r}-1\right) d$, account for the actual dimensions by deducing the corresponding areas of the fastener holes.

\subsection{Failure modes parallel-to-grain}

Typical failure modes for connections with dowel-type fasteners loaded parallelto-grain are shown in Figure 3 , as originally described by Fahlbusch [12]. Embedment (Fig. 3a is the only one considered to be ductile, as it is based on plastic deformation of both wood and steel fasteners. It is the failure mode described by the European Yield Model (EYM, the Eurocode 5 [3] model), and it therefore is the desired failure mode. It has usually been assumed that it can be achieved by means of adequate spacing $a_{i}$ among the fasteners.

The remaining four failure modes in Figure 3 are all brittle. In splitting (Fig. 3b), a central longitudinal crack forms along the row of fasteners, and it is usually considered to be related to tension perpendicular to the grain.

Row-shear (Fig. 3c) is also produced along the row of fasteners, but it consists on two parallel cracks instead of one. It is formed by the stresses in shear and in tension 
perpendicular-to-the-grain, and crack location is related to the location of the maximum shear stress in the vicinity of the hole.

Block and plug shear failures (sometimes called group tear-out, Fig. 3d) consist on the tearing out of timber in the connection area. They can be described as the failure of three different planes, as shown in Figure 4, which will be referred throughout this paper as tensile plane $\mathbf{H}$, lateral shear planes $\mathbf{L}$ and bottom shear plane $\mathbf{B}$. Different failure modes may happen, depending on the combination of failed planes, as depicted in Fig. 4. Block-shear is usually referred only to connections with large-diameter fasteners which protrude the whole timber member, and in which the bottom plane $\mathbf{B}$ is not activated (Fig. 4c). In the case of connections with small-diameter fasteners, which do not protrude the whole thickness, this failure mode is usually called plug-shear, and the bottom-plane is part of the failure as well (Figs. 4band 4a).

Tension failure (Fig. 3e) is already covered in the codes, and it is determined by the capacity of the net area of the wood member, $b_{n e t} \times t$. It is not considered in this work.

Any connection may finally end up failing in a brittle manner at its ultimate capacity [45]. However, for a ductile failure to happen, it would be desirable that the brittle failure would occur after fastener yielding, and thus achieving enough ductility. To that mean, the brittle failure capacity of the connection should be higher than both the fastener yielding and ultimate resistance, in order to avoid brittle and mixed failure modes. The different types of failure and their ranges are described and discussed in detail in [46, 30].

\section{Design models for brittle failure of connections loaded parallel-to-grain}

The different model proposals for brittle failure in the parallel-to-grain direction are summarized in this Section, grouped by the failure mode they describe.

Only the New Zealand Standard draft [43] and the proposal from Hanhijärvi and Kevarinmäki [22] provide a consistent set of equations to deal with all the brittle failure modes at once. The Eurocode 5 [3] covers block-shear in its Annex A. It does not have an explicit model for splitting and row-shear. However, the effective number of fasteners derives from a model which accounted for splitting and shear [16], so it may be assumed that splitting and row-shear failures are implicitly taken into account in this reduction factor.

All the equations have been rewritten according to the nomenclature given in Figure 1 The relevant equations are described in each corresponding mode, although in some cases that might be not completely correct according to the complete model.

A particular remark must be made for the model of Hanhijärvi and Kevarinmäki [22]. It provides formulae to account for the capacity of the inner and outer parts of the connection, and the total capacity of the connection is obtained as the sum of both. Although provided, they do not describe equations for each failure mode in the same way as this paper does. Therefore, equations shown herein are derived from their proposal. They additionally consider a reduction in the capacity of the planes failing by shear and tension due to the interaction between parallel-to-grain tension, parallel-tograin shear and perpendicular-to-grain tension stress components. As shown in Sjödin and Johansson [47], highly stressed areas under different stresses overlap, and they 
Table 1: Proposals for splitting of connections loaded in the parallel-to-grain direction. Shown strength refers to the capacity of the timber member, with exception of the Eurocode 5, where the reduction factor to be applied to the number of fasteners to obtain the capacity of the connection is given.

\begin{tabular}{|c|c|c|c|}
\hline Reference & Strength & $\beta_{p}$ & Remarks \\
\hline Literature & & \multirow{5}{*}{$\frac{1}{10}$} & \multirow{4}{*}{$\begin{array}{l}\text { Different beginning locations. } s_{t 90, i} \\
\text { are geometric parameters. } k_{\text {conc }}= \\
0.7\end{array}$} \\
\hline Jorissen 16 & $2 t \sqrt{\frac{G_{f} E_{0} d \sin \alpha(b-d \sin \alpha)}{b}}$ & & \\
\hline $\begin{array}{l}\text { Hanhijärvi and Ke- } \\
\text { varinmäki [22] }\end{array}$ & $\left\{\begin{array}{l}\frac{k_{\text {conc }}}{\beta_{p}} \frac{1}{s_{t 90, h o l e}} a_{3} t f_{t, 90} \text { (hole) } \\
\frac{k_{\text {conc }}}{\beta_{n}} \frac{1}{s_{000}} a_{3} t f_{t, 90} \text { (end) }\end{array}\right.$ & & \\
\hline $\begin{array}{l}\text { Jockwer et al. } 48 \\
\text { Standards }\end{array}$ & $2 \beta_{p} t a_{3} f_{t, 90}$ & & \\
\hline Eurocode $5[3$ & $\left\{\begin{array}{l}n_{c}^{0.9} \sqrt[4]{\frac{a_{1}}{13 d}} \text { (dowels) } \\
n_{c}^{k_{e f}} \quad \text { (nails) }\end{array}\right.$ & & $\begin{array}{l}\text { Reduction factor of the ductile capac- } \\
\text { ity per shear-plane of the connection. }\end{array}$ \\
\hline
\end{tabular}

therefore propose an interaction effect for the stress components which results in a reduced capacity. They used the following interaction equation:

$$
F_{i+j}=F_{i}\left(1-k_{i n t} \frac{F_{i}}{F_{j}}\right), \text { being } F_{i} \leq F_{j} ;
$$

where $k_{\text {int }}=0.3$ is the interaction factor, and $F$ are the plane capacities. It is considered for their model in this work.

\subsection{Splitting failure}

The splitting capacity of the timber members defined by the different models are given in Table 1. Splitting consists on a single crack in the vicinity of the holes (Figure $3 \mathrm{~b}$ ), and it is assumed to be produced by tension perpendicular-to-the-grain. Most of the proposals contain a geometrical condition for it, with different wedge factors (relation between the perpendicular-to-grain and parallel-to-grain stresses).

The value of this wedge parameter, which defines the value of the perpendicularto-grain stresses, depends on the friction between the dowel and the timber in the hole. This results in a different position (defined by an angle $\alpha$ ) for the maximum perpendicular-to-grain stress from which the wedge value is derived. In his seminal work, Jorissen [16] considered two possibilities for this wedge parameter: $\beta_{p}=\frac{1}{10}$, corresponding to a friction angle $\alpha=30^{\circ}$, and $\beta_{p}=\frac{1}{7}\left(\alpha=18^{\circ}\right)$. As shown in Table 1 , $\beta_{p}=\frac{1}{10}$ is used by Hanhijärvi and Kevarinmäki [22], and $\beta_{p}=\frac{1}{7}$ by Jockwer et al. [48], following the work of Schmid [49]. Recently, Jensen et al. [50] have found out that a higher factor $\beta_{p}=0.25$ might provide a better correlation to experimental results.

The work from Jorissen [16], based on a Timoshenko-beam on elastic foundation accounting for the developed shear stresses by means of a Volkersen model [51], is also the basis for the effective number of fasteners $n_{e f}$ proposed in the Eurocode 5 [3], which lowers the capacity obtained by means of the EYM. This reduction factor is a way to implicitly include splitting in the design model, by reducing the ductile capacity of the connection. Since it is not properly defined as a brittle failure mode, 
Table 2: Proposals for row shear failure. Shown strength refers to the capacity of the timber member, with exception of the Eurocode 5, where the reduction factor to be applied to the number of fasteners to obtain the capacity of the connection is given.

\begin{tabular}{|c|c|c|}
\hline Reference & Strength & Remarks \\
\hline \multicolumn{3}{|l|}{ Literature } \\
\hline $\begin{array}{l}\text { Hanhijärvi and Kevarin- } \\
\text { mäki [22] }\end{array}$ & $2 k_{v, \text { cnctr }} \frac{n_{e f}}{n_{c}} L_{c} t_{e f} f_{v}$ & $n_{e f}=n_{c}^{0.9}$ \\
\hline Quenneville [23] [40] & $2 J_{r} n_{c} n_{r} t a_{L, \min } f_{v}$ & $\begin{array}{l}0.6 \leqslant J_{r} \leqslant 1, \text { function of } n_{r} . \\
a_{L, \min }=\min \left\{a_{1}, a_{3}\right\}\end{array}$ \\
\hline $\begin{array}{l}\text { Jensen and Quenneville } \\
35\end{array}$ & $\min \left\{\begin{array}{l}2 n_{c} n_{r} t a_{1} f_{v} \\
2 n_{c} n_{r} t a_{3} f_{v} \\
2 \Phi t a_{3} f_{v}{ }^{a}\end{array}\right.$ & $\begin{array}{l}\Phi, \text { function of fracture energy, row position } \\
\text { (inner, outer) and connection geometry. }\end{array}$ \\
\hline \multicolumn{3}{|l|}{ Standards } \\
\hline Eurocode 5 & $n_{e f}= \begin{cases}n_{c}^{0.9} \sqrt[4]{\frac{a_{1}}{13 d}} & \text { (dowels) } \\
n_{c}^{k_{e f}} & \text { (nails) }\end{cases}$ & $\begin{array}{l}\text { Reduction factor of the ductile capacity per } \\
\text { shear-plane of the connection. }\end{array}$ \\
\hline $\begin{array}{l}\text { New Zealand Standard } \\
\text { draft } 43\end{array}$ & $2 K_{L S} 0.75 n_{c} n_{r} t a_{L, \min } f_{v}$ & $K_{L S}=\left\{\begin{array}{l}0.65 \text { (outer members) } \\
1.0 \text { (inner members) }\end{array}\right.$ \\
\hline
\end{tabular}

Security and reduction factors from standards have been omitted

${ }^{a}$ This expression is only valid for a symmetric connection with one fastener.

Similar expressions are derived for other configurations.

it is the only model which does not calculate the capacity of the timber member, but obtains the splitting capacity from the ductile mode capacity per shear plane.

The fracture-based model developed by Jorissen [16] was later simplified by Hanhijärvi and Kevarinmäki [22], and has recently been revised by Jockwer et al. [48]. In terms of fracture mechanics [52], splitting can be considered a Mode I crack extension (the resulting crack is produced by tension perpendicular to it) [48, 53]. The capacity of fracture-based proposals is obtained from the amount of energy required to open of the crack in the relevant mode, $G_{f}$. Therefore, they are very sensitive to its value (as it will later be shown). In this work, the required fracture energy $G_{f}$ is obtained from Jockwer [48, 54].

\subsection{Row-shear failure}

Row-shear failure consists on two longitudinal cracks along the row of fasteners in the grain direction (Figure 3c). Contrary to splitting, in terms of fracture mechanics [52], it can be considered a mixed mode crack extension between Modes I and II (they are produced from both tension and in-plane shear stresses) [53]. The strength of a single timber member for row-shear proposed by each model is briefly described in Table 2. As previously explained for splitting, no explicit model for row-shear is given in the current version of the Eurocode 5 [3]. However, it is implicitly included in the already referred $n_{e f}[16,51]$.

Hanhijärvi and Kevarinmäki [22] proposed a geometrical expression for the capacity of the failure shear plane of each row. The plane is defined by the whole length of the connection $L_{c}$, and a depth equal to an effective thickness, which considers the 
influence of the dowel slenderness. Since there is an uneven load distribution among the fasteners in a row, an effective number of fasteners $n_{e f}=n^{0.9}$ is used to reduce the resulting capacity. Additionally, the obtained shear capacity is lowered as a result of the interaction with the tension capacity in the connection, as shown in (1).

Another geometrical model was proposed by Quenneville [23]. However, in this case, instead of the failure plane of the whole row, it is assumed that the shortest plane between two fasteners (thus the one with the minimum $a_{1}$ or $a_{3}$ distances) triggers the failure of the whole row. This approach was included in the Canadian Code O86 [39, 24], and in the New Zealand Standard draft [43] with minor differences in its parameters.

It was found to be the plastic limit of the later developed fracture-based model by Jensen and Quenneville [35, 36, 37]. For intermediate conditions, a different expression was proposed, in which the parameter $\Phi$ derives from a comprehensive set of equations (not given in this work) which accounted for the different geometrical (spacings -parallel and perpendicular-to-grain-, position of the row and the dowel -inner, outer-...) and material properties (fracture energy) of the timber member, and the chosen failure criterion (maximum shear stress or mean stress) [35-37].

\subsection{Block-shear and plug-shear failures}

The group-tear-out (block-shear and plug-shear, Figure 3d) failures consist on the complete tear-out of the timber attached to the group of fasteners in the lateral $\mathbf{L}$, bottom $\mathbf{B}$ (for plug-shear) and tensile $\mathbf{H}$ planes (see Figure 4). Hence, most of the models obtain the capacity of the timber member from the capacity of some or all of these planes. Table 3 gives an overview of the different models, shows the capacity for each failure plane $(\mathbf{H}, \mathbf{L}$ and $\mathbf{B})$, and how the capacity of the timber member is obtained as a combination of those of the considered planes.

The models differ in the way they obtain the connection capacity from the planes' capacity. Some of them propose to add the single plane capacities [55, 28], while others consider as the connection capacity the minimum among the plane capacities [27, 42].

The proposals from the Eurocode 5 [3] and Johnsson and Parida [26] consider as the joint capacity that of the plane with the maximum capacity, as the other planes will have failed previously to final failure [11, 56]. Johnsson and Parida [26] take into account only the bottom and head planes, because they found out experimentally that the lateral planes fail in advance, and they therefore do not contribute to the ultimate connection capacity.

Quite a different approach is given in the New Zealand draft [43] for the case of plug-shear with small-diameter fasteners: based on the work by Zarnani and Quenneville [46, 29], the connection capacity is obtained from a spring model of the three planes accounting for the relative stiffness $\Gamma_{i}$ of each of them, as given in Table 5

Some of the models consider an effective thickness $t_{e f}$ for the failed planes different than the whole member thickness. They are summarized in Table 4 They are mainly based on the distance between the hinges in the corresponding plastic EYM mode. Only the approach from Zarnani and Quenneville [46], included in the New Zealand Standard draft [43], uses a beam-on-elastic-foundation model when the brittle failure is produced in the elastic range, before fastener yielding, and a similar plastic-based thickness for the post-elastic behaviour. 


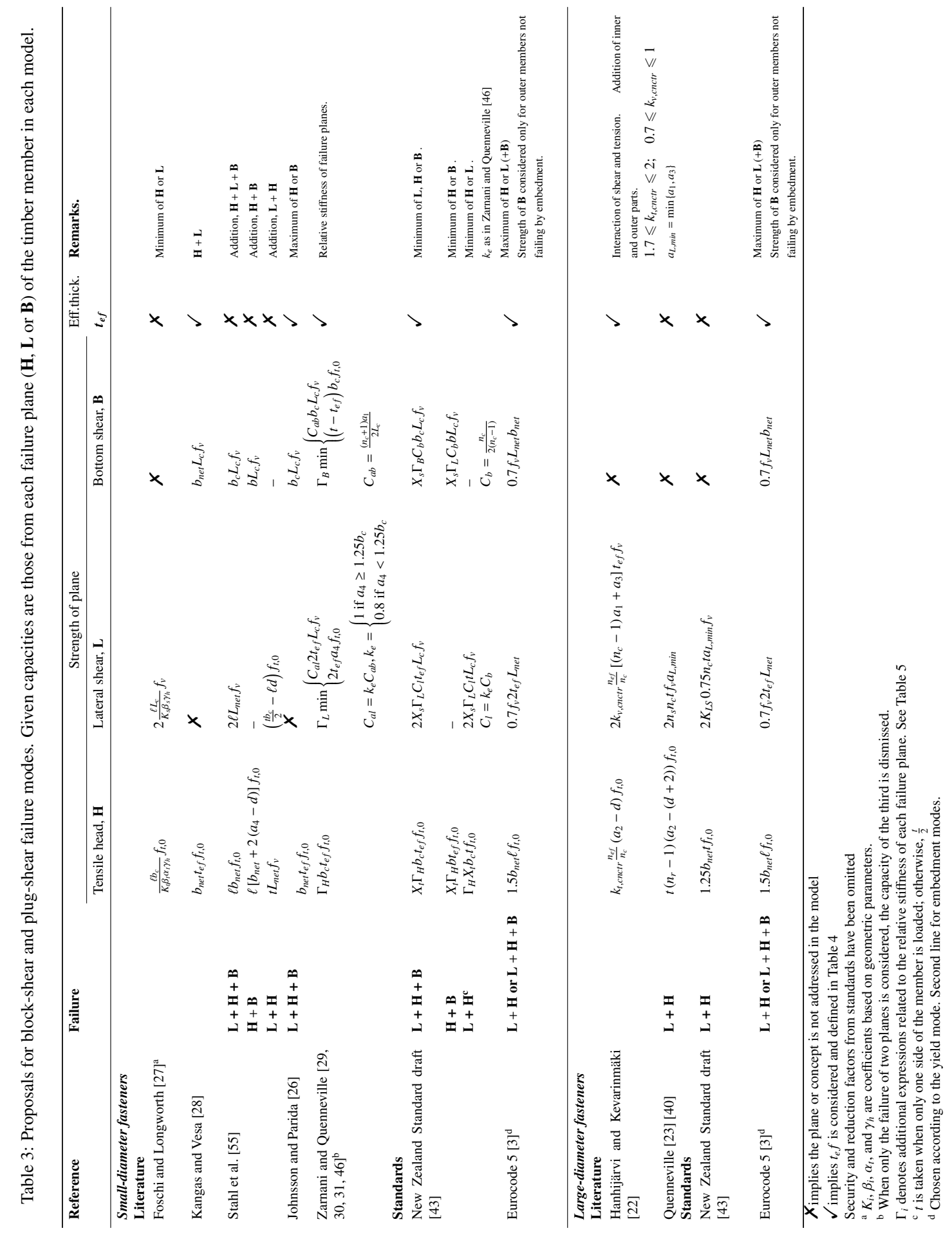


Table 4: Effective thickness considered on the different approaches for block-shear and plug-shear failures in Table 3

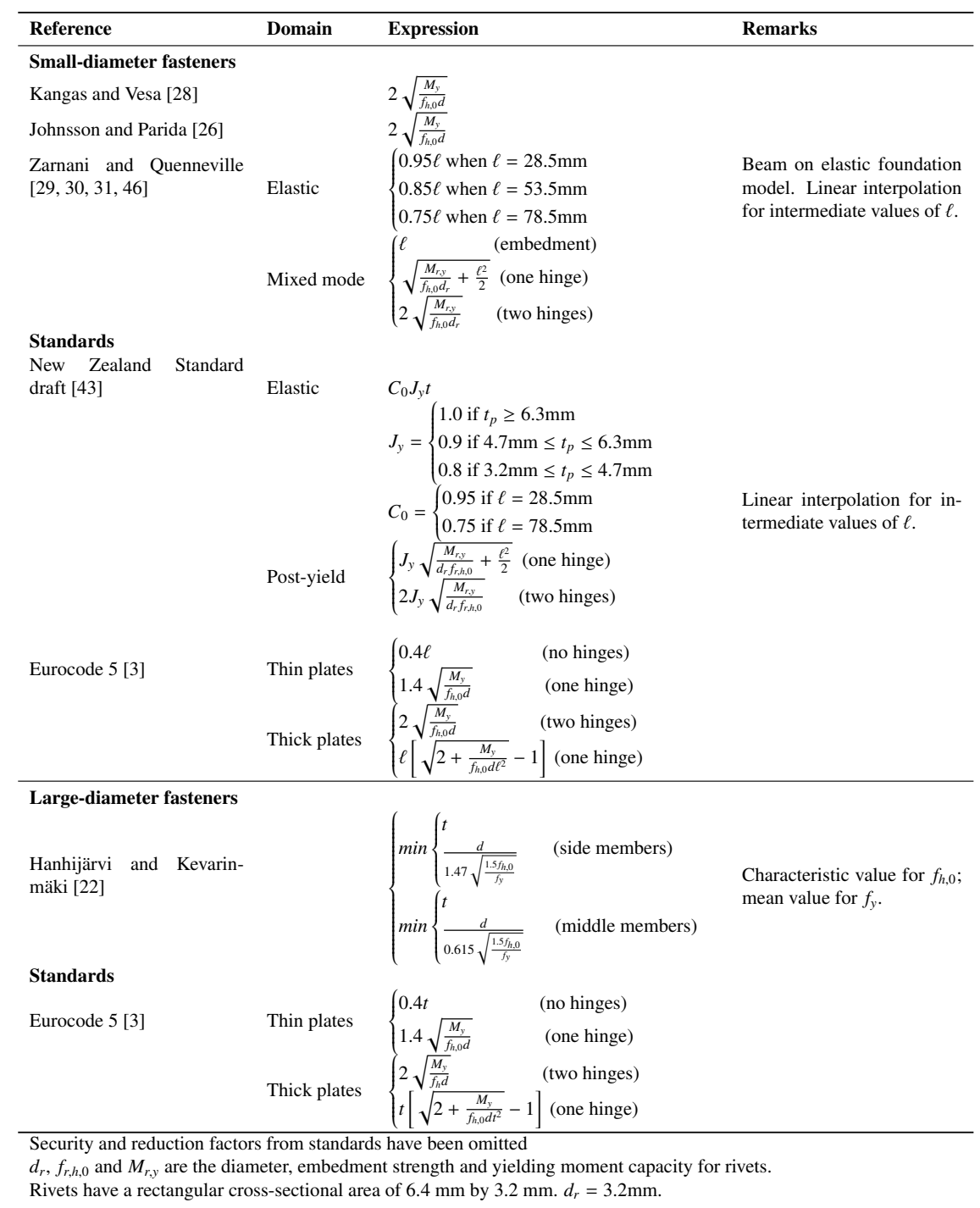


Table 5: Stiffness parameters for the New Zealand approach for plug-shear failure.

\begin{tabular}{|c|c|c|c|}
\hline Reference & $\Gamma_{H}$ & $\Gamma_{B}$ & $\overline{\Gamma_{L}}$ \\
\hline $\begin{array}{l}\text { Zarnani and Quenneville } \\
311^{\mathrm{a}, \mathrm{b}}\end{array}$ & $\frac{K_{H}+K_{B}+K_{L}}{K_{H}}$ & $\frac{K_{H}+K_{B}+K_{L}}{K_{B}}$ & $\frac{K_{H}+K_{B}+K_{L}}{K_{L}}$ \\
\hline Used parameters & $K_{H}=\frac{2 E b_{c} t_{e f}}{L_{c}-a_{3}}$ & 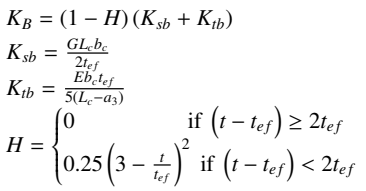 & $\begin{array}{l}K_{L}=(1-F)\left(K_{s l}+K_{t l}\right) \\
K_{S l}=\frac{2 L_{c} t_{e} G}{b_{c}} \\
K_{t l}=\frac{E_{c} b_{c}}{5\left(L_{c}-b_{c}\right)} \\
F= \begin{cases}0 & \text { if } a_{4} \geq 1.25 b_{c} \\
0.16\left(2.5-\frac{2 a_{4}}{b_{c}}\right)^{2} & \text { if } a_{4}<1.25 b_{c}\end{cases} \end{array}$ \\
\hline \multirow[t]{2}{*}{$\begin{array}{l}\text { New Zealand Standard } \\
\text { draft }[43]^{c}\end{array}$} & $1+\lambda_{1}+\lambda_{2}$ & $1+\frac{1}{\lambda_{1}}+\lambda_{3}$ & $1+\frac{1}{\lambda_{2}}+\frac{1}{\lambda_{3}}$ \\
\hline & $\lambda_{1}=\frac{K_{B}}{K_{H}}$ & $\lambda_{2}=\frac{K_{L}}{K_{H}}$ & $\lambda_{3}=\frac{K_{L}}{K_{B}}$ \\
\hline
\end{tabular}

${ }^{a}$ Equations are rewritten according to the nomenclature used in this paper.

${ }^{\mathrm{b}}$ When only two planes are involved, the stiffness of the third is dismissed.

${ }^{c}$ Defines $\lambda_{i}$ parameters for ease of use. Their relationship to 31 is given.

Table 6: Tests on connections with large-diameter fasteners loaded parallel-to-the-grain. Some tests reported more than one failure mode, so the sum of percentages is higher than $100 \%$.

\begin{tabular}{|c|c|c|c|c|c|c|c|c|c|}
\hline & & $\begin{array}{l}\text { Jensen and Quen- } \\
\text { neville [37] }\end{array}$ & $\begin{array}{l}\text { Mohammad and } \\
\text { Quenneville [40] }\end{array}$ & $\begin{array}{l}\text { Quenneville and } \\
\text { Mohammad 39] }\end{array}$ & $\begin{array}{l}\text { Sjödin and Jo- } \\
\text { hansson 47] }\end{array}$ & Iraola 57] & $\begin{array}{l}\text { Hanhijïrvi and Ke- } \\
\text { varinmäki [22] }\end{array}$ & & tal \\
\hline \multirow{2}{*}{$\begin{array}{l}\text { No. of config. } \\
\text { No. of tests }\end{array}$} & & 16 & 30 & 46 & 6 & 13 & 30 & 141 & - \\
\hline & & 104 & 300 & 460 & 30 & 38 & 98 & 1030 & - \\
\hline \multirow{3}{*}{$\begin{array}{l}\text { Joint scheme } \\
\text { (Figure 2) }\end{array}$} & $W S(\mathrm{Fig} 2 \mathrm{C}$ & - & 9 & - & - & - & - & 9 & $7.2 \%$ \\
\hline & SWS (Fig z्व & 16 & - & 46 & - & - & 17 & 63 & $50.4 \%$ \\
\hline & $W S W$ (Fig ze & - & 21 & - & 6 & 13 & 13 & 53 & $42.4 \%$ \\
\hline \multirow{3}{*}{ Joint config. } & 1 fastener & 8 & 9 & 6 & - & 3 & - & 26 & $18.4 \%$ \\
\hline & 1 row & 8 & 8 & 1 & - & 10 & - & 27 & $19.2 \%$ \\
\hline & Group & - & 13 & 39 & 6 & - & 30 & 88 & $62.4 \%$ \\
\hline \multirow{2}{*}{ Fastener } & Bolt & 16 & 30 & 46 & - & - & - & 92 & $62.4 \%$ \\
\hline & Dowel & - & - & - & 6 & 13 & 30 & 49 & $34.8 \%$ \\
\hline \multirow[t]{3}{*}{ Timber product } & LVL & 16 & - & - & - & - & 17 & 33 & $23.4 \%$ \\
\hline & $\mathrm{GL}$ & - & 22 & 45 & 6 & - & 13 & 86 & $61.0 \%$ \\
\hline & Lumber & - & 8 & 1 & - & 13 & - & 22 & $15.6 \%$ \\
\hline \multirow[t]{5}{*}{ Failure mode } & Ductile & 3 & - & 9 & - & - & - & 12 & $8.5 \%$ \\
\hline & Splitting & 14 & 1 & 9 & - & 13 & - & 37 & $26.2 \%$ \\
\hline & Row & - & 22 & 26 & 6 & - & 3 & 57 & $40.4 \%$ \\
\hline & Block & - & 18 & 11 & 3 & - & 26 & 58 & $41.1 \%$ \\
\hline & Tension & - & - & - & - & - & 3 & 3 & $2.1 \%$ \\
\hline
\end{tabular}

\section{Procedure for the benchmarking of design approaches by experiments}

\subsection{Experimental data reported in literature}

A summary of tests related to brittle failure on connections loaded parallel-to-grain reported in literature is given in Table 6 for large diameter fasteners (bolts and dowels) and Table 7 for small-diameter fasteners (nails and rivets). Both provide a brief description of the main features of the compiled data set, such as number and type of configurations tested (as described in Figure 2), used timber product, and reported failure mode. All the compiled tests are tension tests.

Some works analyzed the influence of the moisture content and its variation in the brittle capacity (i.e. Sjödin and Johansson [47]). Only those tests where the timber members were around the reference moisture content of $12 \%$ were considered.

In the case of large-diameter fasteners, more than a thousand individual tests, grouped in 141 different configurations conform the database. Almost all of them are doubleshear configurations, with a central steel plate (WSW, 42.4\%) or with side steel plates $(S W S, 50.4 \%)$. Some of the featured tests are single dowel (18.4\%) and single-row 
Table 7: Tests on connections with small-diameter fasteners loaded parallel-to-the-grain.

\begin{tabular}{|c|c|c|c|c|c|c|c|c|}
\hline & & $\begin{array}{l}\text { Zarnani and } \\
\text { Quenneville [46] }\end{array}$ & $\begin{array}{l}\text { Zarnani and } \\
\text { Quenneville [29] }\end{array}$ & $\begin{array}{l}\text { Foschi and Long- } \\
\text { worth 27] }\end{array}$ & $\begin{array}{l}\text { Johnsson } \\
\text { Parida } 26]\end{array}$ & and & & otal \\
\hline \multicolumn{2}{|l|}{ No. of config. } & 32 & 8 & 10 & 22 & & 72 & - \\
\hline \multicolumn{2}{|l|}{ No. of tests } & 102 & 24 & 30 & 91 & & 247 & - \\
\hline \multirow{2}{*}{$\begin{array}{l}\text { Joint scheme } \\
\text { (Figure 2) }\end{array}$} & WS (Fig 2a & - & - & 10 & 22 & & 32 & $44.4 \%$ \\
\hline & SWS (Fig 2b) & 32 & 8 & - & - & & 40 & $55.6 \%$ \\
\hline \multirow[t]{2}{*}{ Fastener } & Rivet & 32 & 8 & 19 & - & & 50 & $69.4 \%$ \\
\hline & Nail & - & - & - & 22 & & 22 & $30.6 \%$ \\
\hline \multirow[t]{2}{*}{ Timber product } & LVL & 6 & 8 & - & - & & 14 & $17.9 \%$ \\
\hline & GL & 26 & - & 10 & 22 & & 64 & $82.1 \%$ \\
\hline \multirow[t]{2}{*}{ Failure mode } & Ductile & 4 & 2 & 2 & 1 & & 9 & $11.5 \%$ \\
\hline & Brittle & 28 & 6 & 8 & 21 & & 69 & $88.5 \%$ \\
\hline
\end{tabular}

(19.2\%) connections, which may not reflect practice. However, $62.4 \%$ of the connections are group of fasteners, more similar to current practice. Different types of timber products are present, being glulam $(61 \%)$ the best represented. From the perspective of the different failure modes, the majority of them failed in a brittle mode. Around $40 \%$ of the brittle failures are row-shear or block-shear. Only $26 \%$ failed due to splitting. However, this type of failure is mostly seen in connections with a single row or fastener, which are not common in practice.

A total of 72 different connection configurations (247 individual tests), with roughly half of them in a WS single-shear configuration and the other half in double-shear SWS have been compiled for small-diameter fasteners. From them, $88.5 \%$ experienced brittle failure. Most of the tests used rivets $(69.4 \%)$ as fasteners.

It is worth noticing that some of the tests come from the experimental campaign originally developed to derive some of the models. In those cases, they conform the validation space against which those particular models were originally calibrated.

\subsection{Benchmarking procedure}

\subsubsection{Levels of comparison}

Two different levels of comparison may be established for the comparison of the models and the experimental results: mean and characteristic. However, literature usually reports experimental mean values and the corresponding coefficient of variation, while the different material properties are usually given at the characteristic level.

Since most of the compiled tests have few replicates, (usually three, and just a few of them as much as ten [40]), obtaining a relevant characteristic test value [58] as desirable, is nevertheless doubtful.

To provide a common framework and methodology, the corresponding material properties used in the model for each test are taken from the relevant standards or other available technical documentation [59,60, 38, 32, 61] according to the type of product and originally reported strength class (all the compiled tests provided such information). However, as said, the given strength values are at a characteristic level and must be converted to mean values to allow the comparison to the mean experimental values. The probabilistic model for timber porposed by the JCSS [62] has been used to obtain the required mean material properties with a script developed within the framework of the COST Action FP1402 [63, 64]. 
The same procedure was done to obtain the mean fastener properties from the nominal properties, by means of the corresponding probabilistic model [65]. However, the influence of the steel properties is quite irrelevant, with the exception of the $n_{e f}$ parameter in the Eurocode 5.

Therefore, both test results and material properties are assessed at the mean level. However, although not discussed here, the comparison at the characteristic level was done as well, providing similar results.

\subsubsection{Metrics to measure model performance}

It is advisable to use more than one metric to provide an adequate evaluation of the performance of the different models [66-71]. It is suggested to calculate them at a $95 \%$ confidence level, after eliminating the tests with the highest residuals to dismiss any outlier predictions, judging or measurement errors [70]. The sections below provide an explanation of the different metrics used for the performance assessment in this work.

No single metric can replace a scatter plot in which the experimental results are compared to the model results. A complementary visual inspection of the scatter plots is always needed in order to notice problems which the metrics may obscure [72]. Hence, the corresponding scatter plots are given as a reliable tool to additionally estimate the calibration of each model in Figures 5 to 8 .

\section{Overall performance measures.}

Coefficient of determination A general procedure to verify model fitting of the models is the coefficient of determination $Q^{2}$ [66, 73],

$$
Q^{2}=1-\frac{\sum_{i=1}^{n}\left(y_{i}-f_{i}\right)^{2}}{\sum_{i=1}^{n}\left(y_{i}-\bar{y}\right)^{2}},
$$

where $y_{i}$ are the observed experimental values, $f_{i}$ are the predicted values by the models, and $\bar{y}$ is the mean of the experimental values. Eq. (2) may give negative values [68] when it is not applied to regression fitting, as is the case herein. In those cases (as it will be shown) it is just a proof of poor prediction ability. A reliable threshold value for $Q^{2}$ has been found to be 0.70 [72]. Although extensively used, the validity of the $Q^{2}$ metric as a reliable source to assess performance of models is highly questionable [67-70].

Additional criteria and different metrics to verify the validity of a model have been proposed as replacement [67,68]. In this study, the concordance correlation coefficient $(C C C)[71,73,72]$ is used. It is here rewritten for the current comparison case as

$$
C C C=\frac{2 \sum_{i=1}^{n}\left(f_{i}-\bar{f}\right)\left(y_{i}-\bar{y}\right)}{\sum_{i=1}^{n}\left(f_{i}-\bar{f}\right)^{2}+\sum_{i=1}^{n}\left(y_{i}-\bar{y}\right)^{2}+n(\bar{f}-\bar{y})^{2}},
$$

where $n$ is the number of experiments, and $\bar{f}$ the mean of the predicted values. This parameter measures both precision (error between the predictions $f_{i}$ and the experimental values $y_{i}$ ) and accuracy (how much the model deviates from the slope 1 line passing through the origin). It has been demonstrated to be more reliable than other similar metrics for model validation, with a recommended threshold value of 0.85 [73, 72]. 
Error measurement In order to obtain a simple expression of the error, the mean relative error $M R E$ is defined as

$$
M R E=\frac{1}{n} \frac{\sum_{i=1}^{n} y_{i}-f_{i}}{\bar{y}} .
$$

Relative errors of around $10 \%$ are usually agreed as adequate. The standard deviation of this mean error $S D$ will be given as well.

Correlation Additionally, it can be of interest to find models which are able to provide a good correlation, although they may provide quantitatively wrong predictions. Two different correlation measurements are used in this work.

A rank correlation coefficient $c$ [68] provides information on the relative ranking, that is, on the ability of each model to order the tests correctly according to their capacity, independently of the quantitative predictions. A higher correlation coefficient implies a better model.

The slope $m$ of a linear fit passing through the origin is another way to measure the observed correlation between values. Although it provides no adequate measure of the degree of accuracy [68], it gives an idea of how conservative or unconservative the model is. Slopes close to one are usually proof of a good model correlation.

Evaluation of characteristic over-prediction, $R_{5}$. The final aim of this review is to consider the models as candidates for a future design standard. Such documents are written to provide predictions at a characteristic level, which is further transformed to a design level. A good model, previously to the use of additional factors in the code, should provide a performance similar to a 5-percentile (characteristic) prediction, meaning that the capacity of a number of tests close to the 5-percentile of the total number should be over-predicted, and the capacity of most of the tests should be under-predicted.

Therefore, as an additional check, the corresponding metric $R_{5}$ is evaluated. It represents the relative amount of tests for which the models, when they are used with characteristic material properties, over-predict the mean test value. A value for this parameter of $0.05(5 \%)$ or lower, would mean a better fit of the model within the current design standards practice, as it fulfills the safety condition that approximately only $5 \%$ of the tests are over predicted.

Discrimination. The validity of a model can be related as well to its ability to discriminate between brittle and ductile failures [66]. Therefore, such discrimination power is also assessed in this work (see Section 5.5).

\section{Results of the benchmarking}

For the assessment of the reviewed proposals, each approach is evaluated against those tests which have been reported to fail in such manner, i.e. the splitting methods are evaluated against the connections which have been reported to fail in splitting. 
Table 8: Splitting. Comparison of the different models, ordered from the highest (best) to the lowest $C C C$.

\begin{tabular}{lcccccc}
\hline Model & $Q^{2}$ & $M R E(S D)$ & $m$ & $c$ & $C C C$ & $R_{5}$ \\
\hline Eurocode 5 [3] & 0.736 & $0.263(0.304)$ & 1.057 & 0.872 & 0.868 & 0.444 \\
Jockwer et al. [48] & 0.422 & $0.338(0.368)$ & 0.970 & 0.705 & 0.719 & 0.037 \\
Hanhijärvi and Kevarinmäki [22] & -2.498 & $0.786(0.948)$ & 1.616 & 0.794 & 0.487 & 0.444 \\
Jorissen [16] & -0.162 & $0.518(0.483)$ & 0.474 & 0.615 & 0.342 & 0.074 \\
\hline
\end{tabular}

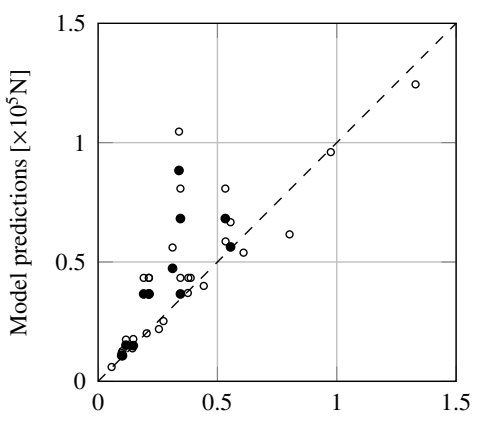

Exp. mean values $\left[\times 10^{5} \mathrm{~N}\right]$

(a) Eurocode 5 [3]

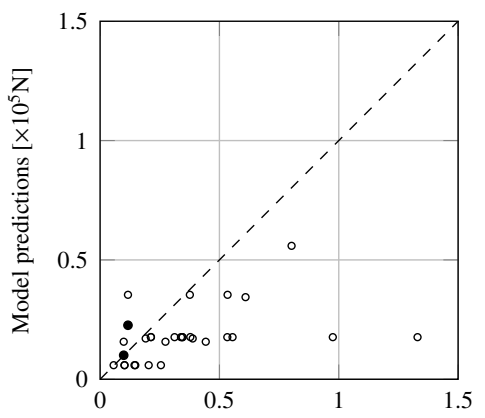

Exp. mean values $\left[\times 10^{5} \mathrm{~N}\right]$

(c) Jorissen 16

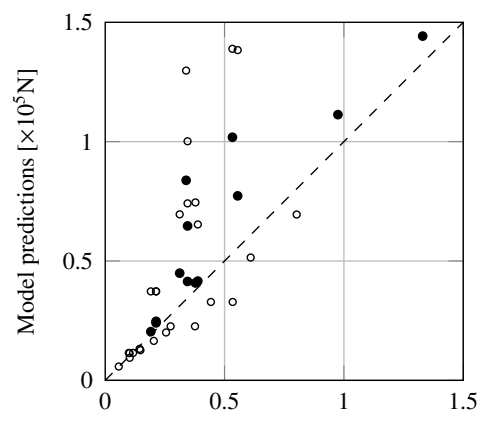

Exp. mean values $\left[\times 10^{5} \mathrm{~N}\right]$

(b) Hanhijärvi and Kevarinmäki [22]

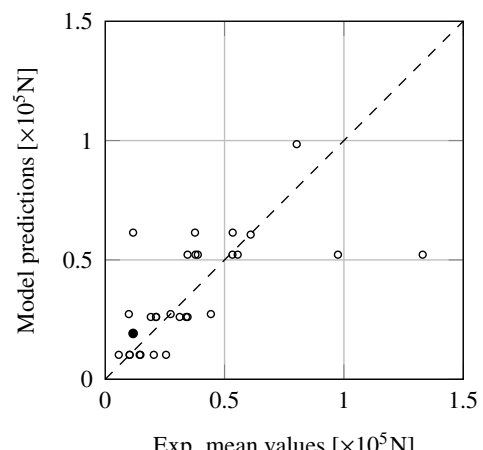

(d) Jockwer et al. 48

Figure 5: Splitting. Scatter plots of the experimental mean results and the predicted value from different approaches (with mean material properties). Filled dots represent the values that are overpredicted when characteristic material properties are applied, represented by $R_{5}$. 


\subsection{Splitting}

The results for the benchmarking of the different splitting models are given in Table 8 , with the corresponding scatter plots in Figure 5 .

Just two of the models, Eurocode 5 [3] and Jockwer et al. [48] have a positive coefficient of determination $Q^{2}$. On the other hand, Hanhijärvi and Kevarinmäki [22] and Jorissen [16] obtain a negative $Q^{2}$. This lack of predictive ability is additionally proved by their mean error, which is higher than 0.5 . It is clear in the corresponding scatter plots, Figs. $5 \mathrm{~b}$ and $5 \mathrm{c}$

The slopes of the fitted linear regression through the origin $m$ are an additional proof of the predicting ability of the different models. Those models with a positive coefficient of determination have a slope close to one, while the others do not obtain such a good agreement: Hanhijärvi and Kevarinmäki [22] tends to overpredict, and Jorissen [16] to underpredict.

The correlation coefficient $c$ provides a different point of view, as it does not consider the quantitative agreement. The best correlated model, Eurocode 5 [3], is the one with the highest $Q^{2}$ coefficient; but the second best, Hanhijärvi and Kevarinmäki [22], is the one with the worst $Q^{2}$. However, only the ability of the model to order the results in the correct order is assessed which, for cases such as the one studied here, may not be not enough.

It is interesting to notice how the $C C C$ parameter provides an appropriate summary of the precedent metrics. The Eurocode model [3] gets a score over the defined threshold for a good model $(C C C \geq 0.85)$. Jockwer et al. [48] gets the second best $C C C$ coefficient, and due to its better correlation performance, the model of Hanhijärvi and Kevarinmäki [22] get the third best value, although it obtained a negative $Q^{2}$.

The fracture-based model from Jorissen [16] obtains the worst result. However, one important remark must be made: due to the lack of availability of the fracture energy values for the different timber products, the same value for lumber (obtained from Jockwer [54]) had to be used for the whole data set. Fracture energy values are yet to be included in daily available technical documents in order for these models to be used.

Only the models from Jockwer et al. [48] and Jorissen [16] obtain low $R_{5}$ values, close to the desired threshold of 0.05 . However, this fact could be improved for the other models by means of a calibration parameter. The over-predicted tests are filled in black in Figure 5, to provide a feeling about their number and distribution.

\subsection{Row-shear failure}

In the previous section, it was shown how the $C C C$ metric provides a simple way to measure the performance of the models, in a similar way to what it is reflected in the corresponding scatter plots and in the different additional metrics. For the sake of brevity, the following discussion will mainly refer to this $C C C$ parameter. The corresponding Tables will still show the remaining metrics for completeness.

When looking at the plots of the different models in Figure 6, two of the models, New Zealand Standard draft [43] and Hanhijärvi and Kevarinmäki [22], obtain values close to the ideal correlation depicted with the dashed line. Due to its lower scatter and error, the model from Hanhijärvi and Kevarinmäki [22] gets the best $C C C$ value. 


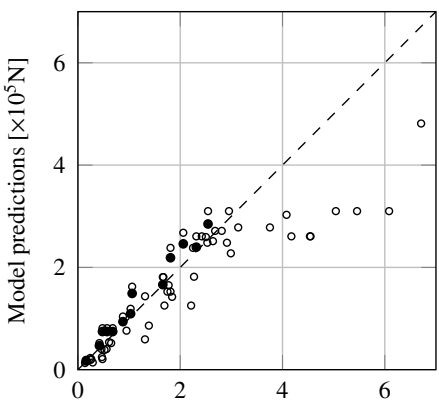

Exp. mean values $\left[\times 10^{5} \mathrm{~N}\right]$

(a) Eurocode $5[3$

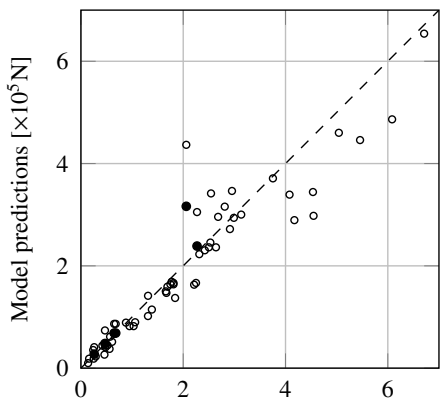

Exp. mean values $\left[\times 10^{5} \mathrm{~N}\right]$

(c) Hanhijärvi and Kevarinmäki [22

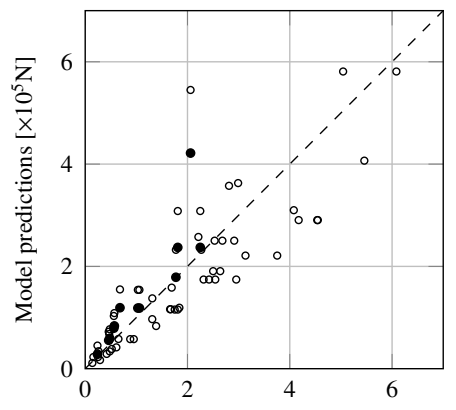

Exp. mean values $\left[\times 10^{5} \mathrm{~N}\right]$

(b) New Zealand Standard draft [43]

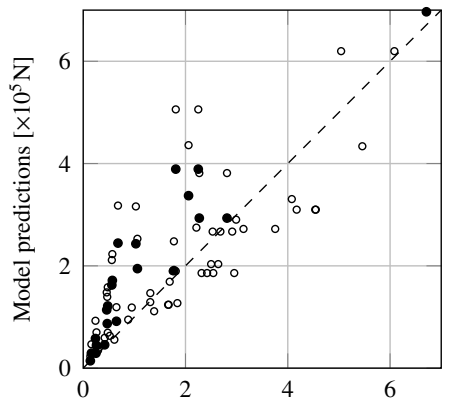

Exp. mean values $\left[\times 10^{5} \mathrm{~N}\right]$

(d) Quenneville [23]

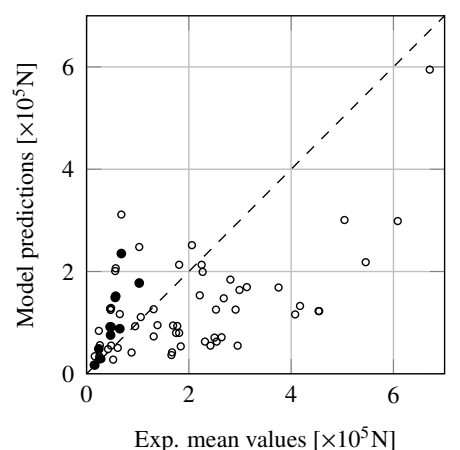

(e) Jensen and Quenneville 35

Figure 6: Row-shear failure. Scatter plots of the experimental mean results and the predicted value from different approaches (with mean material properties). Filled dots represent the values that are overpredicted when characteristic material properties are applied $\left(R_{5}\right)$. 
Table 9: Row-shear failure. Comparison of the different models, ordered from the highest to the lowest $C C C$.

\begin{tabular}{lcccccc}
\hline Model & $Q^{2}$ & $M R E(S D)$ & $m$ & $c$ & $C C C$ & $R_{5}$ \\
\hline Hanhijärvi and Kevarinmäki [22] & 0.928 & $0.142(0.159)$ & 0.910 & 0.977 & 0.961 & 0.105 \\
New Zealand Standard draft [43] & 0.780 & $0.279(0.224)$ & 0.855 & 0.913 & 0.877 & 0.228 \\
Eurocode 5 [3] & 0.778 & $0.227(0.278)$ & 0.803 & 0.942 & 0.862 & 0.228 \\
Quenneville [74] & 0.635 & $0.353(0.328)$ & 1.003 & 0.794 & 0.819 & 0.386 \\
Jensen and Quenneville [35] & 0.182 & $0.556(0.455)$ & 0.560 & 0.483 & 0.486 & 0.193 \\
\hline
\end{tabular}

Table 10: Block shear failure. Comparison of the different models, ordered from the highest to the lowest CCC.

\begin{tabular}{lcccccc}
\hline Model & $Q^{2}$ & $M R E(S D)$ & $m$ & $c$ & $C C C$ & $R_{5}$ \\
\hline Hanhijärvi and Kevarinmäki [22] & 0.552 & $0.180(0.182)$ & 1.134 & 0.939 & 0.826 & 0.227 \\
New Zealand Standard draft [43] & -0.045 & $0.290(0.234)$ & 0.898 & 0.688 & 0.569 & 0.159 \\
Quenneville [74] & -0.483 & $0.277(0.348)$ & 1.196 & 0.711 & 0.528 & 0.273 \\
Eurocode 5 [3] & -0.286 & $0.319(0.263)$ & 0.919 & 0.613 & 0.523 & 0.159 \\
\hline
\end{tabular}

It also obtains the lowest (and therefore best) $R_{5}$ metric, with a $10 \%$ of the tests over predicted for characteristic values in the model.

The implicit model of the Eurocode 5 [3], the $n_{e f}$ parameter, gets a good $C C C$ metric, slightly worse than that of the New Zealand Standard draft [43]. The scatter plot (Fig. 6a) shows a reduction on its prediction ability for high capacities, which it tends to under-predict. It may be related to the fact that it is a reduction factor of the EYM ductile capacity. The higher error in the high-capacity region of the Eurocode 5 [3] model is described by the standard deviation metric of the model, shown in brackets in Tab. 9, higher than the one of the New Zealand Standard draft [43].

As happened in the previous Section for the fracture-based splitting model of Jorissen [16], the fracture-based model from Jensen and Quenneville [37] gets the worst score. However, as noted above, it is not a proof of worse predicting ability, but of the lack of information available on the fracture energy $G_{f}$.

\subsection{Block-shear failure}

The results for the benchmarking of the different block models are given in Table 10 Only the model from Hanhijärvi and Kevarinmäki [22] gets a good value of the $C C C$ metric, with comparable performance in the other metrics.

Due to the huge variety of different configurations in the experimental tests and the high range of analysed data, all the remaining models obtain negative coefficients of determination $Q^{2}$. However, the scatter plots do not describe such a bad agreement, as also proved by their correlation factors $(c \geq 0.6)$, and their $C C C$ values, around 0.5 for all of them. The negative $Q^{2}$ values are mainly due to the fact of the high mean errors and corresponding standard deviations obtained.

\subsection{Plug-shear failure}

The results for the benchmarking of the different plug-shear models are given in Table 11. Additionally, since the models were originally proposed for different fasten- 


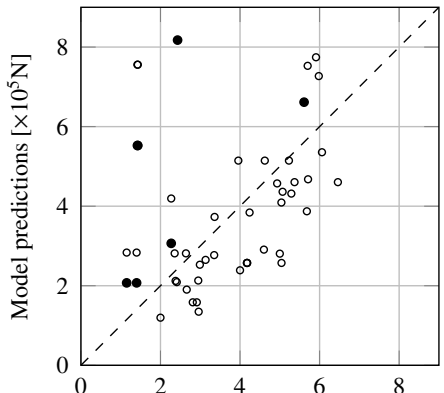

Exp. mean values $\left[\times 10^{5} \mathrm{~N}\right]$

(a) Eurocode $5[3$

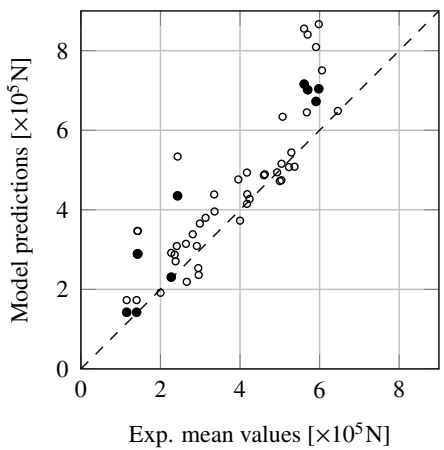

(c) Hanhijärvi and Kevarinmäki [22]

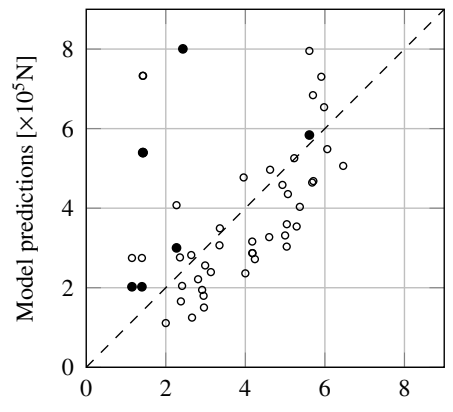

Exp. mean values $\left[\times 10^{5} \mathrm{~N}\right]$

(b) New Zealand Standard draft [43]

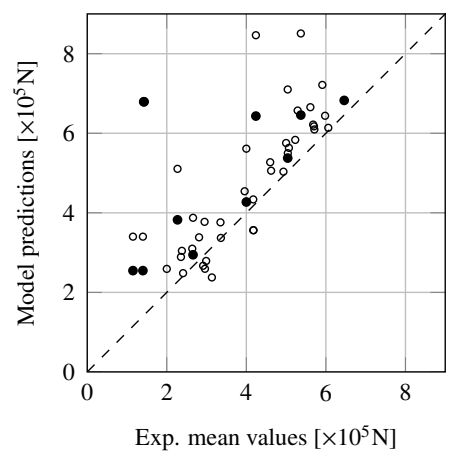

(d) Quenneville 23]

Figure 7: Block-shear failure. Scatter plots of the experimental mean results and the predicted value from different approaches (with mean material properties). Filled dots represent the tests that are overpredicted when characteristic material properties are applied $\left(R_{5}\right)$.

Table 11: Plug-shear failure. Comparison of the different models, ordered from the highest to the lowest CCC.

\begin{tabular}{lcccccc}
\hline Model & $Q^{2}$ & $\operatorname{MRE}(S D)$ & $m$ & $c$ & $C C C$ & $R_{5}$ \\
\hline Kangas and Vesa [28] & 0.700 & $0.224(0.144)$ & 0.983 & 0.895 & 0.874 & 0.150 \\
New Zealand Standard draft [43] & 0.535 & $0.239(0.182)$ & 0.831 & 0.846 & 0.788 & 0.083 \\
Eurocode 5 [3] & 0.359 & $0.310(0.193)$ & 0.979 & 0.787 & 0.754 & 0.217 \\
Johnsson and Parida [26] & 0.385 & $0.257(0.241)$ & 0.730 & 0.839 & 0.638 & 0.133 \\
Stahl et al. [55] & -4.780 & $0.977(0.69)$ & 1.955 & 0.891 & 0.403 & 0.833 \\
\hline
\end{tabular}




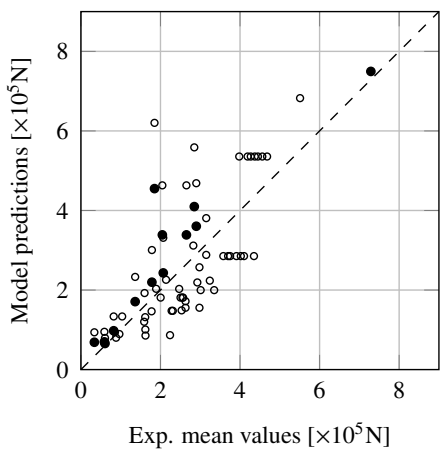

(a) Eurocode 5 [3]

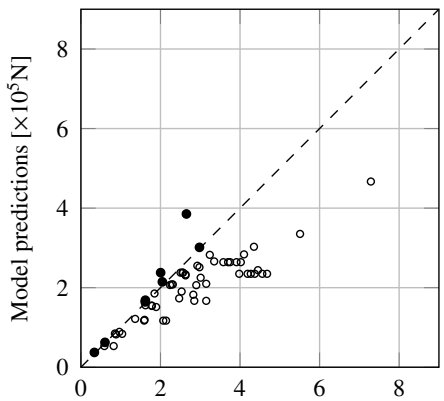

Exp. mean values $\left[\times 10^{5} \mathrm{~N}\right]$

(c) Johnsson and Parida 26

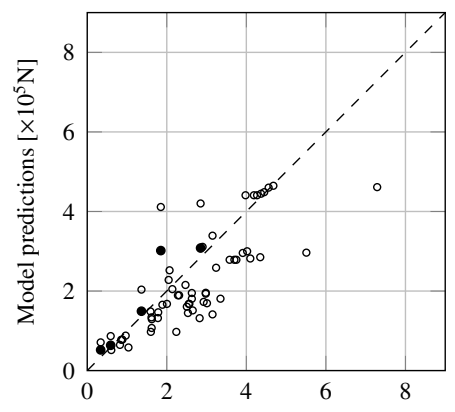

Exp. mean values $\left[\times 10^{5} \mathrm{~N}\right]$

(b) New Zealand Standard draft [43]

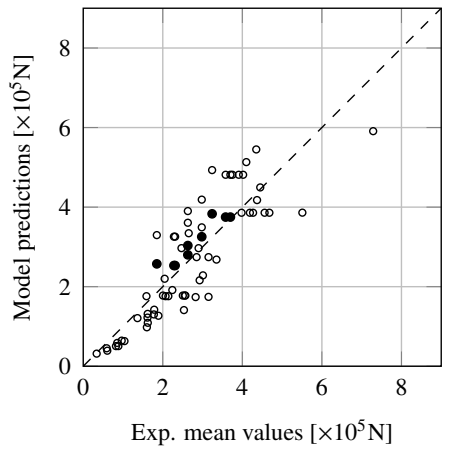

(d) Kangas and Vesa [28]

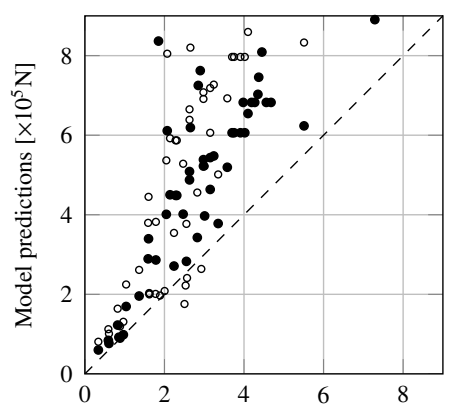

Exp. mean values $\left[\times 10^{5} \mathrm{~N}\right]$

(e) Stahl et al. [55]

Figure 8: Plug-shear failure. Scatter plots of the experimental mean results and the predicted value from different approaches. Filled dots represent the values that are overpredicted when characteristic material properties are applied $\left(R_{5}\right)$. 
Table 12: Plug-shear failure. Influence of the different type of fastener (nails or rivets) in the performance of the models.

\begin{tabular}{|c|c|c|c|c|c|c|}
\hline \multirow[t]{2}{*}{ Model } & \multicolumn{3}{|c|}{ Nails } & \multicolumn{3}{|c|}{ Rivets } \\
\hline & $Q^{2}$ & $M R E(S D)$ & $\overline{C C C}$ & $Q^{2}$ & $M R E(S D)$ & $C C C$ \\
\hline Kangas and Vesa [28] & 0.502 & $0.301(0.185)$ & 0.712 & 0.669 & $0.228(0.168)$ & 0.826 \\
\hline New Zealand Standard draf & 0.404 & $0.315(0.225)$ & 0.582 & 0.218 & $0.231(0.2)$ & 0.687 \\
\hline Eurocode $5[3]$ & 0.409 & $0.322(0.212)$ & 0.591 & 0.413 & $0.318(0.188)$ & 0.783 \\
\hline Johnsson and Parida 26 & 0.830 & $0.135(0.159)$ & 0.903 & -0.191 & $0.307(0.218)$ & 0.436 \\
\hline Stahl et al. 55 & 0.350 & $0.317(0.252)$ & 0.669 & -6.016 & $1.181(0.485)$ & 0.284 \\
\hline
\end{tabular}

ers, namely nails and rivets, Table 12 shows a summary of the obtained values for the tests with each type of connector (nails or rivets).

Most of the available tests have been made for rivets (only the tests from Johnsson and Parida [26] were done with nails -see Table 7f-) and, therefore, most of the proposals have been validated for rivets, not for nails. The only ones which were developed for nails are those from Eurocode 5 [3] and Johnsson and Parida [26]. However, and since brittle failure is related to timber, it may be assumed that, for similar connection areas, the type of connector might play a minor role in the resulting brittle capacity.

The model from Kangas and Vesa [28] qualifies as the best predictor, as proved by its superior metrics.

The model in the New Zealand Standard draft [43] gets the second position in terms of the concordance correlation coefficient. It gets a lower coefficient of determination, comparable error and tends to underpredict, as shown by its slope. However, maybe due to this fact it gets the best ratio for characteristic values in the model. The model in the Eurocode 5 [3] gets a similar $C C C$ value, thanks to its good slope, although the remaining metrics are worse, including the performance at characteristic level.

The model from Stahl et al. [55] consistently over-predicts, as shown in Fig. 8e, and therefore gets the worst $C C C$ value. However, it obtains one of the highest correlation factors. It is the only studied model which does not use an effective thickness $t_{e f}$.

Due to the fact that two quite different small-diameter fasteners are used in the experimental data set (round nails, and rectangular rivets), it is interesting having a look at the performance of the different models for each fastener type, as shown in Table 12 The model proposed by Johnsson and Parida [26] surpasses the others in the case of nails. However, being theirs the only tests with nails, it is just a proof of the good validation with their own tests. Kangas and Vesa [28] obtains the second best CCC score. The model from Johnsson and Parida [26] gets lower performance when compared only to those tests with rivets, while the remaining models (proposed for rivets) improve. The model from Kangas and Vesa [28] remains as one of the best.

\subsection{Discrimination ability}

As previously explained, an additional interesting metric in this particular study is the ability to correctly predict the failure mode of the connection, whether ductile or brittle. An additional consideration would be related to the safety level for false predictions: predicting a false ductile failure could lead to unsafe results; while a false brittle prediction would lead to a conservative design. 


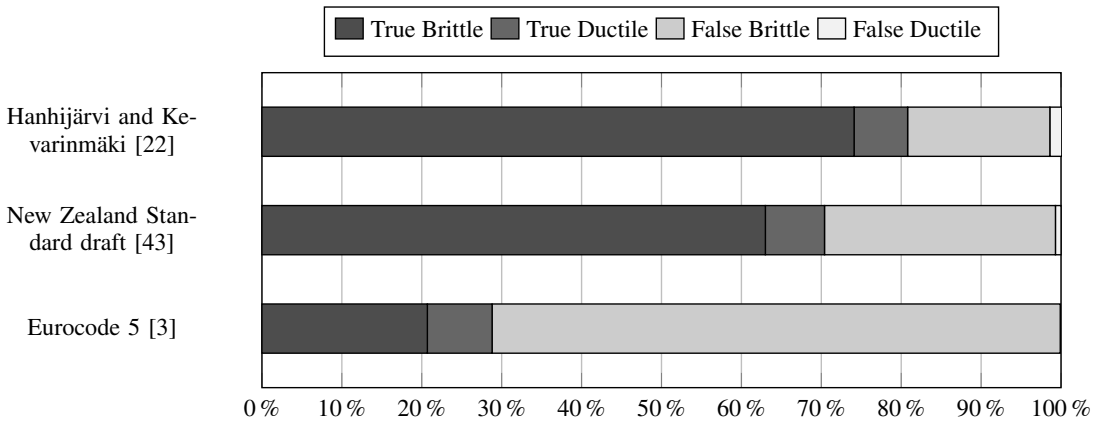

(a) Large-diameter fasteners

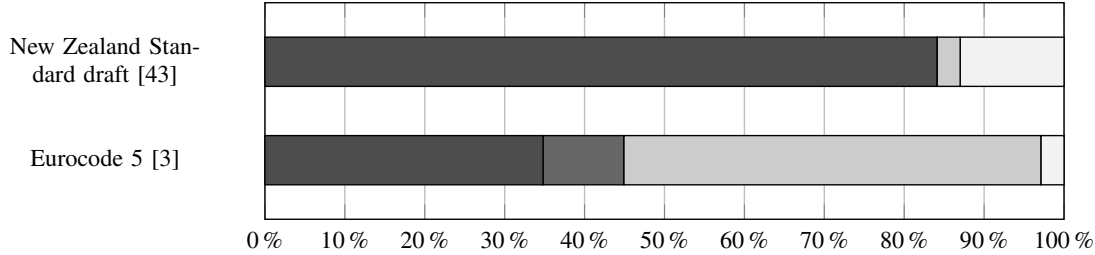

(b) Small-diameter fasteners

Figure 9: Discrimination ability. Comparison between Eurocode 5 [3], New Zealand Standard draft [43] and Hanhijärvi and Kevarinmäki [22].

Only the design standards, Eurocode 5 [3], New Zealand Standard draft [43], and the proposal from Hanhijärvi and Kevarinmäki [22] are somehow comprehensive proposals which allow for a complete discrimination for dowels; and only the design standards [3, 43] allow for it in the case of small-diameter fasteners. The rest of the reviewed models are models for a single failure mode.

However, the system proposed in the current Eurocode faces a problem when evaluated this way. Since it does not explicitly consider splitting or row-shear, it cannot predict a ductile failure: the supposed ductile EYM failure is always a brittle failure, as it is always the result of reducing the ductile capacity with the $n_{e f}$ parameter. Only those tests with a single fastener (not allowed in the Eurocode, but in which the $n_{e f}$ is not applied) can be classified as ductile failure.

In the case of large-diameter fasteners (dowels and bolts), the model from Hanhijärvi and Kevarinmäki [22] provides the best discrimination ability, as shown in Figure $9 \mathrm{a}$ It correctly predicts over $80 \%$ of the failure modes (either ductile or brittle). Not surprisingly, it is consistently ranked as one of the best models for each single failure mode. The model in the New Zealand Standard draft [43] gets a slightly lower discrimination ability (70.4\%), much higher than that obtained with the Eurocode 5 [3] $(28.9 \%)$.

For small-diameter fasteners (Figure 9b), the New Zealand Standard draft [43] is clearly superior to the Eurocode 5 [3]. It correctly predicts over $85.5 \%$ of the compiled experimental sets, against less than $44.9 \%$ for the Eurocode 5 [3]. 


\section{Conclusions}

Having reliable models to verify the brittle failure of timber connections is of utmost importance. This paper reviews several existing models (explained in Sect. 3 ) for brittle failure of timber connections loaded in the parallel-to-grain direction. Their performance against a set of tension tests gathered from literature (Tables 6 and 7) has been compared. The compared models allow to evaluate splitting (Tab. 11), row-shear (Tab. 2), and block and plug-shear (Tab. 3) failures. Special attention has been given to the models included in two design standards, current Eurocode 5 [3] and New Zealand Standard draft [43].

The comparison has been made at the mean level, and for that, the characteristic material properties have been converted to mean values by means of a probabilistic model [62].

The use of the metric $C C C$ (3) has been proposed. It provides a useful measure of the validity of the models, and it has been shown to give a summary of the other metrics (coefficient of determination, mean error, correlation and fitting slope). In any case, it does not replace the scatter plots of experimental and predicted values, which give a clear view of the models' validity.

The $n_{e f}$ model included in the current Eurocode 5 [3] for splitting and row-shear is the best for splitting. However, this implicit inclusion of failure modes is not advisable, since it does not inform in an appropriate way to the designer about the expected failure mode. The models from Hanhijärvi and Kevarinmäki [22] and New Zealand Standard draft [43] get better results in the case of row-shear.

The Annex A of Eurocode 5 [3], which deals with block and plug-shear is one of the least reliable models. It is the worst model for block-shear, where the model from Hanhijärvi and Kevarinmäki [22] is the best one; and it is surpassed by the models from Kangas and Vesa [28] and New Zealand Standard draft [43] for plug-shear failure.

The model for dowelled connections developed by Hanhijärvi and Kevarinmäki [22] gets the best results for row-shear and block-shear failures. At the same time, it is the model which best discriminates ductile and brittle failure for large-diameter fasteners. It seems as a viable alternative to the models currently included in the standards for dowelled connections.

The New Zealand Standard draft [43] consistently gets the second best position in its considered failure modes: row-shear, block-shear and plug-shear. It does not take splitting into account which is, however, a rare failure in current practice connections with more than one row. At the same time, it gets the best discrimination ability as a comprehensive system for both large and small-diameter fasteners.

In the case of plug-shear, a simple model such as the one proposed by Kangas and Vesa [28] is the best one, instead of more elaborate alternatives, such as the one developed by Zarnani and Quenneville [29] (included in the New Zealand Standard draft [43]).

The designer should be able to evaluate possible brittle failure modes in connections, so he gets to avoid them in his design. The lack of knowledge shown by the survey conducted within the COST Action [6] proves that design standards should include each failure mode in a clear and explicit way. It is expected that they will be included in the main matter of the future version of the Eurocode 5 (see [6] for more 
information). This work is a first step to provide background information for its development. Further future works will provide insight into each one of the different failure modes, in order to assess the influence of geometrical parameters in this type of failures.

\section{Acknowledgement}

Both authors would like to acknowledge the contribution of the COST Action FP1402, supported by COST (European Cooperation in Science and Technology), for the development of this work, especially the related discussion within the Working Group 3 "Connections". Authors wish to place on record their thanks to the members of the Working Group CEN/TC250/SC5/WG5 "Connections", within the Working Commission of the Eurocode 5, for their valuable comments.

The second author is supported by a PhD fellowship from the Programa de Becas FPU del Ministerio de Educación y Ciencia (Spain) under the grant number FPU15/03413. He would also like to thank the Asociación de Amigos of the University of Navarra for their help with a fellowship in early stages of this research.

\section{References}

[1] E. Frühwald, E. Serrano, T. Toratti, A. Emilsson, S. Thelandersson, Design of safe timber structures - How can we learn from structural failures in concrete, steel and timber? Design of safe timber structures - Report TVBK-3053, Tech. Rep., Lund University, 2007.

[2] E. Frühwald, Analysis of structural failures in timber structures: Typical causes for failure and failure modes, Engineering Structures 33 (11) (2011) 2978-2982, ISSN 01410296, doi:10.1016/j.engstruct.2011.02.045

[3] Eurocode 5, CEN:EN 1995-1-1:2004 - Eurocode 5: Design of timber structures - Part 1-1: General - Common rules and rules for buildings, Comité Européen de Normalisation, 2004.

[4] K. W. Johansen, Theory of Timber Connections, International Association of Bridge and Structural Engineering 9 (1949) 249-262, doi:10.5169/seals-9703

[5] Biger JP, Bocquet JF, Racher P, Testing and designing the joints for the pavilion of Utopia, in: World Conference on Timber Engineering (WCTE), Whistler, Canada,, Paper 4-3-3, 2000.

[6] M. Stepinac, J. M. Cabrero, K. Ranasinghe, M. Kleiber, Reorganization of the Connections Chapter of the Eurocode 5, Engineering Structures (this issue).

[7] COST Action FP1402 "Basis of Structural Timber Design" - from research to standards, Webpage, URL https://www.costfp1402.tum.de/en/, 2017.

[8] M. Hansson, H. J. Larsen, Recent failures in glulam structures and their causes, Engineering Failure Analysis 12 (5 SPEC. ISS.) (2005) 808-818, ISSN 13506307. 
[9] ENV 1995-1-1:1993. Eurocode 5, Design of Timber Structures, Part 1-1: General Rules and Rules for Buildings., Comité Européen de Normalisation, 1993.

[10] A. Ranta-Maunus, A. Kevarinmäki, Reliability of timber structures. Theory and dowel-type connection failures, in: CIB-W18 Timber Structures, Colorado, USA, Paper 36-7-11, 2003.

[11] P. Racher, STEP/Eurofortech, Timber Engineering Volume, vol. 1, chap. Lecture C1. Mechanical timber joints - General, Centrum Hout, Almere, The Netherlands, 1994.

[12] H. Fahlbusch, Ein Beitrag zur Frage der Tragfaehigkeit von Bolzen in Holz bei statischer Belastung, Ph.D. thesis, Technische Hochschule Braunschweig, 1949.

[13] H. Blaß, Load distribution in nailed joints, in: CIB-W18 Timber structures, Lisbon, Portugal, Paper 23-7-2, 1990.

[14] W. Nozynski, Investigation of the effect of number of nails in a joint on its load carrying ability, in: CIB W-18 Timber Structures, Otaniemi, Finland, Paper 137-2, 1980 .

[15] E. Gehri, Design of joints and frame corners using dowel-type fasteners, in: CIBW18 Timber structures,, Bordeaux, France, Paper 29-7-6, 1996.

[16] A. J. Jorissen, Double shear timber connections with dowel type fasteners, Ph.D. thesis, TU Delft, 1998.

[17] M. Yasumura, T. Murota, H. Nakai, Ultimate properties of bolted joints in gluedlaminated timber, in: CIB-W18 Timber structures, Dublin, Ireland., Paper 20-7$3,1987$.

[18] G. Steck, Efectiveness of multiple fastener joints according to national codes and Eurocode 5 draft, in: CIB W-18 Timber Structures, Florence, Italy, Paper 19-7-3, 1986.

[19] I. Smith, G. Steck, Influence of number of rows of fasteners or connectors upon the ultimate capacity of axially loaded timber joints, in: CIB W-18 Timber Structures, Beit Oren, Israel, Paper 18-7-3, 1985.

[20] A. Kevarinmäki, STEP/Eurofortech, Timber Engineering Volume, vol. 2, chap. Lecture E6. Trusses made from laminated veneer lumber, Centrum Hout, Almere, The Netherlands, 1995.

[21] R. Jockwer, Impact of varying material properties and geometrical parameters on the reliability of shear connections with dowel type fasteners, in: International Network on Timber Engineering Research (INTER), vol. 1052, Graz, Austria, Paper 49-7-2, 2016.

[22] A. Hanhijärvi, A. Kevarinmäki, VTT publications 677: Timber Failure Mechanisms in High-Capacity Dowelled Connections of Timber to Steel, VTT, Espoo, ISBN 9789513870904, 2008. 
[23] P. Quenneville, Predicting the failure modes and strength of brittle bolted connections, in: Proceedings of the 5th World Conference on Timber Engineering (WCTE), vol. 2, Montreux, Switzerland, 137-144, 1998.

[24] M. Mohammad, P. Quenneville, Behaviour of wood-steel-wood bolted glulam connections, in: CIB-W18 Timber Structures, Graz, Austria, Paper 32-7-1, 1999.

[25] H. Johnsson, L. Stehn, Plug shear failure in nailed timber connections, Holz als Roh- und Werkstoff (2004) 455-464ISSN 0018-3768.

[26] H. Johnsson, G. Parida, Prediction model for the load-carrying capacity of nailed timber joints subjected to plug shear, Materials and Structures 46 (12) (2013) 1973-1985, ISSN 1359-5997, doi:10.1617/s11527-013-0030-8.

[27] R. Foschi, J. Longworth, Analysis and design of griplam nailed connections, J Struct Div 101 (12) (1975) 2537-2555.

[28] J. Kangas, J. Vesa, Design on timber capacity in nailed steel-to-timber joints, in: CIB-W18 Timber Structures, Savonlinna, Finland, Paper 31-7-4, 1998.

[29] P. Zarnani, P. Quenneville, Group Tear-Out in Small-Dowel-Type Timber Connections: Brittle and Mixed Failure Modes of Multinail Joints, Journal of Structural Engineering 141 (2) (2014) 4014110, ISSN 0733-9445, doi:10.1061/(asce) st.1943-541x.0001053.

[30] P. Zarnani, P. Quenneville, Strength of timber connections under potential failure modes: An improved design procedure, Construction and Building Materials 60 (2014) 81-90, ISSN 09500618, doi:10.1016/j.conbuildmat.2014.02.049

[31] P. Zarnani, P. Quenneville, Wood Block Tear-Out Resistance and Failure Modes of Timber Rivet Connections: A Stiffness-Based Approach, Journal of Structural

I Engineering 140 (2) (2014) 04013055, ISSN 0733-9445, doi:10.1061/(ASCE)ST. 1943-541X.0000840.

[32] P. Zarnani, Load-Carrying Capacity and Failure Mode Analysis of Timber Rivet Connections, Ph.D. thesis, University of Auckland, 2013.

[33] M. Marjerrison, P. Quenneville, Model for the predictions of the ductile and brittle failure modes (parallel-to-grain) of timber rivet connections, in: CIB-W18 Timber Structures, Bled, Slovenia, Paper 40-7-6, 2007.

[34] A. J. Jorissen, Multiple fastener timber connections with dowel type fasteners, in: CIB-W18 Timber Structures, Vancouver, Canada, Paper 30-7-5, 1997.

[35] J. L. Jensen, P. Quenneville, Fracture mechanics analysis of row shear failure in dowelled timber connections., Wood Science and Technology 44 (4) (2009) 639-653, ISSN 00437719, doi:10.1007/s00226-009-0295-9.

[36] J. L. Jensen, P. Quenneville, Fracture mechanics analysis of row shear failure in dowelled timber connections: asymmetric case, Materials and Structures 44 (4) (2010) 351-360, doi:10.1617/s11527-010-9631-7. 
[37] J. L. Jensen, P. Quenneville, Experimental investigations on row shear and splitting in bolted connections, Construction and Building Materials 25 (5) (2011) 2420-2425, ISSN 09500618, doi:10.1016/j.conbuildmat.2010.11.050.

[38] CSA Standard. O86-09. Engineering design in wood, Canadian Standards Association, 2009.

[39] P. Quenneville, M. Mohammad, On the Failure Modes and Strength of SteelWood-Steel Bolted Timber Connections Loaded Parallel to Grain, Canadian Journal of Civil Engineering 27 (4) (2000) 761-773.

[40] M. Mohammad, P. Quenneville, Bolted wood-steel and wood-steel-wood connections: verification of a new design approach, Canadian Journal of Civil Engineering 28 (2) (2001) 254-263, ISSN 0315-1468, doi:10.1139/100-105.

[41] M. Bickerdike, P. Quenneville, Predicting the row shear failure mode in parallelto-grain bolted connections, 9th World Conference on Timber Engineering 2006, WCTE 20062 (2006) 1511-1518.

[42] P. Quenneville, I. Smith, A. Aziz, M. Snow, I. H. Chui, Generalised Canadian approach for design of connections with dowel fasteners, in: CIB-W18 Timber Strctures, Florence, Italy, Paper 39-7-6, 2006.

[43] New Zealand Standard draft, specific amendments to AS 1720.1-2010, Unpublished, 2017.

[44] A. Hanhijärvi, A. Kevarinmäki, Design method against timber failure mechanisms of dowelled steel-to-timber connections, in: CIB-W18 Timber Structures, Bled, Slovenia, Paper 40-7-3, 2007.

[45] S. A. L. Novis, J. Jacks, P. Quenneville, Predicting the resistance and displacement of timber bolted connections, in: World Conference on Timber Enginnering (WCTE 2016), Vienna, Austria, 2016.

[46] P. Zarnani, P. Quenneville, Design Procedure to Determine the Capacity of Timber Connections under Potential Brittle, Mixed and Ductile Failure Modes, in: CIB-W18 Timber Structure, August, Paper 46-7-3, 2013.

[47] J. Sjödin, C.-J. Johansson, Influence of initial moisture induced stresses in multiple steel-to-timber dowel joints, Holz als Roh- und Werkstoff 65 (1) (2006) 7177, ISSN 0018-3768.

[48] R. Jockwer, G. Fink, J. Köhler, Assessment of existing safety formats for timberconnections - How probabilistic approaches can influence connection design in timber engineering, in: Proc. of the COST Action FP1402 at Graz University of Technology, vol. 1, Graz, Austria, 16-31, 2017.

[49] M. Schmid, Anwendung der Bruchmechanik auf Verbindungen mit Holz, Ph.D. thesis, Universität Karlsruhe, Germany, 2002. 
[50] J. Jensen, U. Girhammar, P. Quenneville, Brittle failure in timber connections loaded parallel to the grain, Proceedings of the Institution of Civil Engineers: Structures and Buildings 168 (10), ISSN 17517702 09650911, doi:10.1680/stbu. 14.00108

[51] O. D. Volkersen, Die Nietkraftverteilung in zugbeanspruchten Nietverbindungen mit konstanten Laschenquerschnitten, Luftfartforschung 35 (1938) 4-47.

[52] I. Smith, E. Landis, M. Gong, Fracture and Fatigue in Wood, Wiley, ISBN 0-47148708-2, 2003.

[53] M. Schmid, H. J. Blaß, R. P. M. Frasson, Effect of Distances, Spacing and Number of Dowels in a Row on the Load Carrying Capacity of Connections with Dowels Failing by Splitting, in: CIB-W18 Timber Structures, Kyoto, Paper 35-7-7, 2002.

[54] R. Jockwer, Structural behaviour of glued laminated timber beams with unreinforced and reinforced notches, Ph.D. thesis, IBK ETH Zurich, 2014.

[55] D. C. Stahl, R. W. Wolfe, M. Begel, Simplified analysis of timber rivet connections, Journal of Structural Engineering 130 (August) (2004) 1272-1279, ISSN 0733-9445, doi:10.1061/(ASCE)0733-9445(2004)130:8(1272).

[56] J.-F. Bocquet, C. Barthram, A. Pineur, L block failure of dowelled connections subject to bending reinforced with threaded rods, in: CIB-W18 Timber structures, Växjö, Sweden, Paper 45-7-3, 2012.

[57] B. Iraola, Simulación del Comportamiento Mecánico de la Madera en Uniones Estructurales y su Aplicación mediante Modelos Tridimensionales de Elementos Finitos, Ph.D. thesis, Universidad de Navarra, 2016.

[58] EN 14358:2016. Timber structures - Calculation and verification of characteristic values, CEN, 2016.

[59] Council of Standards Australia (Ed.), AS/NZS 1328: 1998. Glued laminated structural timber, 1998.

[60] EN 338:2016. Structural timber. Strength classes, CEN, 2016.

[61] Certificate. Kerto-S and LKerto-Q Structural laminated veneer lumber. Date of issue March 24, 2004. Updated May 17,2016, Tech. Rep. 184/03, VTT Expert Services Ltd., 2016.

[62] Joint Committee on Structural Safety (Ed.), JCSS Probabilistic Model Code, chap. 3.5. Properties of Timber, JCSS, 2006.

[63] R. Jockwer, G. Fink, Material properties according to JCCS Probabilistic model code, MatLab script, 2017.

[64] R. Jockwer, G. Fink, K. J., Assessment of the failure behaviour and reliability of timber connections, Engineering Structures (this issue). 
[65] Joint Committee on Structural Safety (Ed.), JCSS Probabilistic Model Code, chap. 3.2. Structural steel, JCSS, 2006.

[66] E. W. Steyerberg, A. J. Vickers, N. R. Cook, T. Gerds, M. Gonen, N. Obuchowski, M. J. Pencina, M. W. Kattan, Assessing the Performance of Prediction Models, Epidemiology 21 (1) (2010) 128-138, ISSN 1044-3983, doi: 10.1097/EDE.0b013e3181c30fb2.

[67] A. Golbraikh, A. Tropsha, Beware of $q^{2}$ !, Journal of Molecular Graphics and Modelling 20 (4) (2002) 269-276, ISSN 1093-3263, doi:10.1016/ S1093-3263(01)00123-1.

[68] D. L. Alexander, A. Tropsha, D. A. Winkler, Beware of $R^{2}$ : Simple, Unambiguous Assessment of the Prediction Accuracy of QSAR and QSPR Models, Journal of Chemical Information and Modeling 55 (7) (2015) 1316-1322, ISSN 15205142, doi:10.1021/acs.jcim.5b00206

[69] K. Roy, P. Chakraborty, I. Mitra, P. K. Ojha, S. Kar, R. N. Das, Some case studies on application of " $r_{m}^{2}$ " metrics for judging quality of quantitative structureactivity relationship predictions: Emphasis on scaling of response data, Journal of Computational Chemistry 34 (12) (2013) 1071-1082, ISSN 01928651, doi: $10.1002 /$ jcc.23231

[70] K. Roy, R. N. Das, P. Ambure, R. B. Aher, Be aware of error measures. Further studies on validation of predictive QSAR models, Chemometrics and Intelligent Laboratory Systems 152 (2016) 18-33, ISSN 18733239, doi:10.1016/j.chemolab. 2016.01 .008

[71] P. Gramatica, A. Sangion, A Historical Excursus on the Statistical Validation Parameters for QSAR Models: A Clarification Concerning Metrics and Terminology, Journal of Chemical Information and Modeling 56 (6) (2016) 1127-1131, ISSN 15205142, doi:10.1021/acs.jcim.6b00088.

[72] N. Chirico, P. Gramatica, Real external predictivity of QSAR models. Part 2. New intercomparable thresholds for different validation criteria and the need for scatter plot inspection, Journal of Chemical Information and Modeling 52 (8) (2012) 2044-2058, ISSN 15499596, doi:10.1021/ci300084j.

[73] N. Chirico, P. Gramatica, Real external predictivity of QSAR models: How to evaluate It? Comparison of different validation criteria and proposal of using the concordance correlation coefficient, Journal of Chemical Information and Modeling 51 (9) (2011) 2320-2335, ISSN 15499596, doi:10.1021/ci200211n.

[74] P. Quenneville, Predicting the Failure Modes and Strength of Brittle Bolted Connections, in: World Conference in Timber Engineering, Montreux, Switzerland, 1998.

[75] K. Roy, I. Mitra, S. Kar, P. K. Ojha, R. N. Das, H. Kabir, Comparative studies on some metrics for external validation of QSPR models, Journal of Chemical 


\begin{tabular}{|c|c|c|}
\hline $\begin{array}{l}763 \\
764\end{array}$ & I & $\begin{array}{l}\text { Information and Modeling } 52 \text { (2) (2012) 396-408, ISSN 15499596, doi:10.1021/ } \\
\text { ci200520g }\end{array}$ \\
\hline $\begin{array}{l}765 \\
766 \\
767\end{array}$ & [76] $\mathrm{F}$ & $\begin{array}{l}\text { P. K. Ojha, I. Mitra, R. N. Das, K. Roy, Further exploring } r_{m}^{2} \text { metrics for valida- } \\
\text { tion of QSPR models, Chemometrics and Intelligent Laboratory Systems } 107 \text { (1) } \\
\text { (2011) 194-205, ISSN 01697439, doi:10.1016/j.chemolab.2011.03.011. }\end{array}$ \\
\hline $\begin{array}{l}768 \\
769 \\
770\end{array}$ & [77] I & $\begin{array}{l}\text { I. Mitra, P. P. Roy, S. Kar, P. K. Ojha, K. Roy, On further application of } r_{m}^{2} \text { as a } \\
\text { metric for validation of QSAR models, Journal of Chemometrics } 24 \text { (1) (2010) } \\
\text { 22-33, ISSN 08869383, doi:10.1002/cem.1268. }\end{array}$ \\
\hline 771 & Nome & enclature \\
\hline 772 & Greek & k Symbols \\
\hline 773 & $\alpha$ & Friction angle between the fastener and the timber in the hole \\
\hline 774 & $\alpha_{t}$ & Tensile stress coefficient [27] \\
\hline 775 & $\beta_{t}, \beta_{s}$ & Stress coefficients (tensile and shear) based on nail spacing [27] \\
\hline $\begin{array}{l}776 \\
777\end{array}$ & $\beta_{p}$ & $\begin{array}{l}\text { Ratio of the perpendicular-to-grain wedging force to the parallel-to-grain fas- } \\
\text { tener load }\end{array}$ \\
\hline 778 & $\gamma_{h}$ & Stress coefficient depending on nail penetration [27] \\
\hline $\begin{array}{l}779 \\
780\end{array}$ & $\Gamma_{i}$ & $\begin{array}{l}\text { Additional expressions related to the relative stiffness of each failure plane } \\
{[43,29,-31,46]}\end{array}$ \\
\hline 781 & $\Phi$ & Factor function of fracture energy, location and geometry [35] \\
\hline 782 & Lowe & er cases \\
\hline 783 & $a_{1}$ & Spacing between columns of fasteners \\
\hline 784 & $a_{2}$ & Spacing between rows of fasteners \\
\hline 785 & $a_{3}$ & Distance to the parallel-to-grain edge \\
\hline 786 & $a_{4}$ & Distance to the perpendicular-to-grain edge \\
\hline 787 & $a_{L, \min }$ & Minimum of $a_{1}$ and $a_{3}$ \\
\hline 788 & $b$ & Width of the wood member \\
\hline 789 & $b_{c}$ & Width of the connection \\
\hline 790 & $b_{\text {net }}$ & Net width of the connection \\
\hline 791 & $c$ & Rank correlation coefficient [68] \\
\hline 92 & $d$ & diameter \\
\hline
\end{tabular}




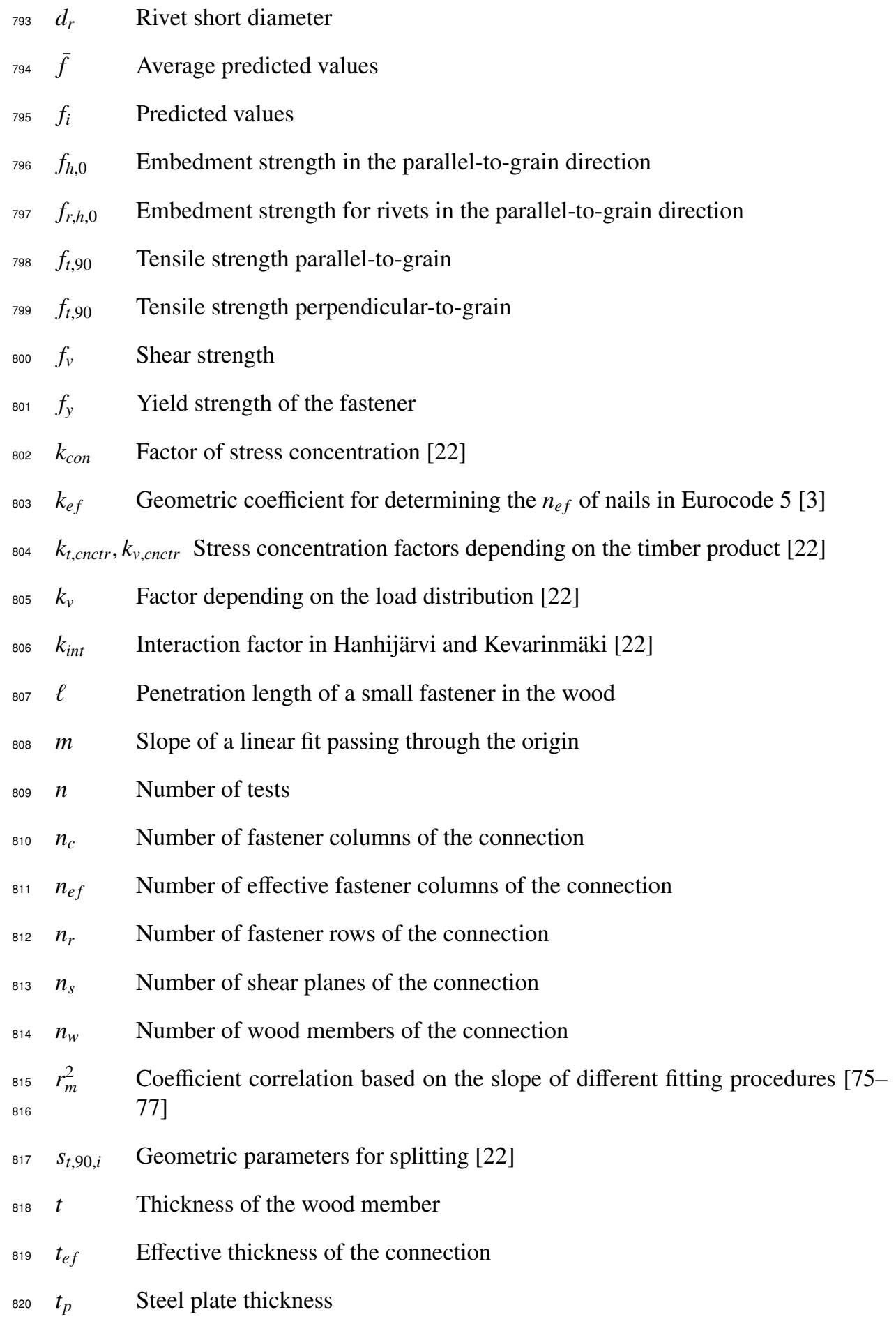




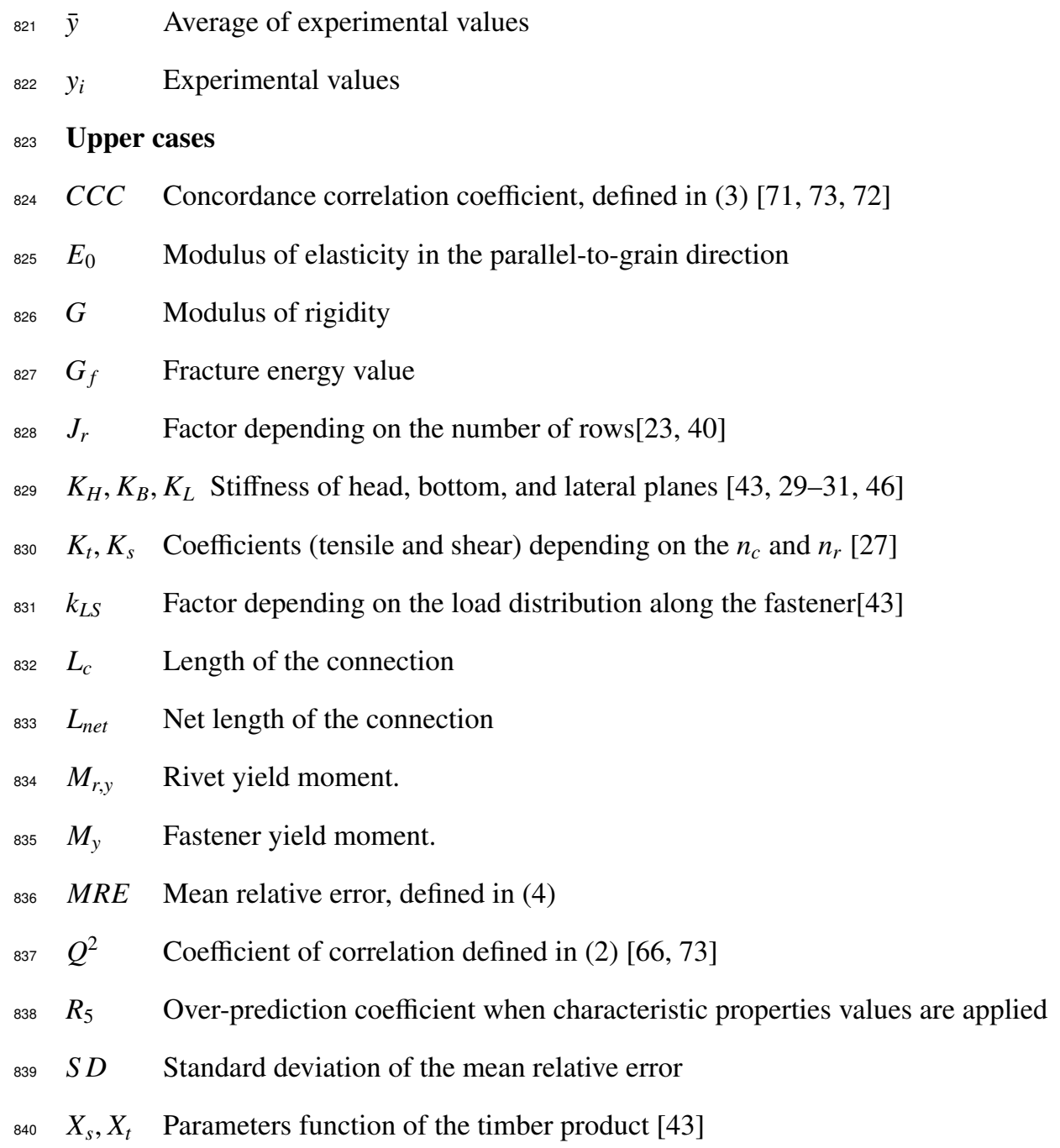

